Article

\title{
Hydrophobically Grafted Pullulan Nanocarriers for Percutaneous Delivery: Preparation and Preliminary In Vitro Characterisation
}

\author{
Mohammad F. Bostanudin 1,*(D), Eugen Barbu ${ }^{2}$ (D) and Kai Bin Liew ${ }^{3}$ \\ 1 College of Pharmacy, Al Ain University, Abu Dhabi 112612, United Arab Emirates \\ 2 School of Pharmacy and Biomedical Sciences, University of Portsmouth, St Michael's Building, \\ White Swan Road, Portsmouth PO1 2DT, UK; eugen.barbu@port.ac.uk \\ 3 Faculty of Pharmacy, University of Cyberjaya, Cyberjaya 63000, Malaysia; liewkaibin@cyberjaya.edu.my \\ * Correspondence: mohammad.bostanudin@aau.ac.ae
}

check for updates

Citation: Bostanudin, M.F.; Barbu, E.; Liew, K.B. Hydrophobically Grafted Pullulan Nanocarriers for Percutaneous Delivery: Preparation and Preliminary In Vitro Characterisation. Polymers 2021, 13, 2852. https://doi.org/10.3390/ polym 13172852

Academic Editors:

Panagiotis Barmpalexis and Konstantinos N. Kontogiannopoulos

Received: 3 August 2021

Accepted: 21 August 2021

Published: 25 August 2021

Publisher's Note: MDPI stays neutral with regard to jurisdictional claims in published maps and institutional affiliations.

Copyright: (c) 2021 by the authors. Licensee MDPI, Basel, Switzerland. This article is an open access article distributed under the terms and conditions of the Creative Commons Attribution (CC BY) license (https:// creativecommons.org/licenses/by/ $4.0 /)$.

\begin{abstract}
Polymeric colloidal nanocarriers formulated from hydrophobically grafted carbohydrates have been the subject of intensive research due to their potential to increase the percutaneous penetration of hydrophilic actives. To this goal, a series of hydrophobically grafted pullulan (BMOPUL) derivatives with varying degree of grafting (5-64\%) was prepared through functionalisation with 2-(butoxymethyl)oxirane. The results demonstrated that monodispersed BMO-PUL nanocarriers (size range 125-185 $\mathrm{nm}$ ) could be easily prepared via nanoprecipitation; they exhibit close-to-spherical morphology and adequate stability at physiologically relevant $\mathrm{pH}$. The critical micellar concentration of BMO-PUL was found to be inversely proportional to their molecular weight (Mw) and degree of grafting (DG), with values of $60 \mathrm{mg} / \mathrm{L}$ and $40 \mathrm{mg} / \mathrm{L}$ for DG of $12.6 \%$ and $33.8 \%$, respectively. The polymeric nanocarriers were loaded with the low Mw hydrophilic active $\alpha$-arbutin (16\% loading), and the release of this active was studied at varying $\mathrm{pH}$ values (5 and 7), with a slightly faster release observed in acidic conditions; the release profiles can be best described by a first-order kinetic model. In vitro investigations of BMO-PUL nanocarriers (concentration range $0.1-4 \mathrm{mg} / \mathrm{mL}$ ) using immortalised skin human keratinocytes cells (HaCaT) evidenced their lack of toxicity, with more than $85 \%$ cell viability after $24 \mathrm{~h}$. A four-fold enhance in arbutin permeation through HaCaT monolayers was recorded when the active was encapsulated within the BMO-PUL nanocarriers. Altogether, the results obtained from the in vitro studies highlighted the potential of BMO-PUL nanocarriers for percutaneous delivery applications, which would warrant further investigation in vivo.
\end{abstract}

Keywords: biopolymers; nanomaterials; polymer synthesis; pullulan; percutaneous

\section{Introduction}

The development of percutaneous drug delivery has aroused enormous interest owing to its potential to avoid first-pass effect and gastrointestinal enzyme-catalysed degradation. Nevertheless, actual progress in the delivery of numerous water-soluble actives has been restrained by their inadequate percutaneous penetration due to the nature of the skin lipid layer that has a high affinity for hydrophobic, ionised, and low molecular weight compounds [1,2]. In an effort to increase the permeation of these actives across the skin, various approaches such as physical (i.e., iontophoresis, magnetophoresis, microneedle, etc.) and chemical (i.e., alcohol, amides, esters, etc.) enhancers have been considered [3]. Despite recent technological advances, harmful side effects such as skin irritation reactions combined with low drug permeability continue to pose major challenges for an effective percutaneous delivery [4,5]. In an alternative approach that shows promising results, ongoing research actively aims at the polymeric colloidal nanocarriers development for percutaneous drug delivery [6-8].

Among the various naturally occurring polymers with potential in drug delivery, of particular interest is pullulan, a widely bioavailable and water-soluble polysaccharide 
synthesised by Aureobasidium pullulans fungus [9]. Well-known for its biodegradability and lack of toxicity, pullulan has been used mainly in the pharmaceutical and food industries [10]. It has been investigated for skin and percutaneous administration, with results suggesting its potential in treating skin wounds and in enhancing percutaneous drug delivery [11-13]. The biogenic synthesis pathway of nanocarriers is considered inexpensive, nontoxic, and eco-friendly $[14,15]$. Biogenic pullulan nanocarriers have shown potential in a variety of applications, including antimicrobial [16], anticancer [17], and antibacterial activities [18]. Pullulan-based nanocarriers have also demonstrated their ability in percutaneous protein delivery [19]. Pullulan possesses functional groups that facilitate a range of chemical modifications that can make it more amenable for use in various applications [20]; for example, when modified into a material with a hydrophobic character, it can spontaneously self-assemble into nanocarriers with a high loading capacity and low critical micellar concentration (CMC) [21,22]. Additional benefits of amphiphilic nanocarriers such as decreased drug cytotoxicity, prolonged blood circulation time, and enhanced permeation make these systems very promising for percutaneous delivery [23-28].

One approach to introduce a degree of hydrophobic character to polysaccharides is alkylation, which results in modified physicochemical properties affecting the membrane permeation ability [29] and ultimately the bioactivity of the whole macromolecule [21,30,31] Different reagents, including epoxide derivatives such as 2-(butoxymethyl)oxirane, can be used to add alkyl groups to hydrophilic polysaccharides. The epoxide ring opening, which is catalysed by a base, transforms it to a hydrophobic alkylglycerol, which may then be grafted onto polysaccharide-free hydroxyl groups to produce hydrophobically grafted polysaccharides [32]. $\alpha$-arbutin, a hydrophilic antioxidant and topical tyrosinase inhibitor, was used as a model drug following studies reporting its poor skin permeability due to the high hydrophilicity of the compound despite being considered as one of the most efficient whitening agents [33-35]. Different studies have lately sought to study the efficient percutaneous administration of $\alpha$-arbutin, both topically and transdermally, to enhance its skin permeability due to its wide variety of uses in various applications [36,37].

To our knowledge, there have been no studies investigating the potential for the percutaneous delivery of $\alpha$-arbutin using nanocarriers formulated from hydrophobically grafted pullulan with 2-(butoxymethyl)oxirane. Investigating the hypothesis that nanoformulations prepared from hydrophobically grafted polymers can provide improved drug carrier characteristics that are suitable for percutaneous delivery, we present here the synthesis and characterisation of hydrophobically grafted pullulan (BMO-PUL) that was grafted with hydrophobic alkylglycerol, 2-(butoxymethyl)oxirane, through a $\mathrm{S}_{\mathrm{N}} 2$ nucleophilic substitution reaction under aqueous alkaline conditions. The formulation and characterisation of their corresponding self-assembled nanocarriers that were formulated via nanoprecipitation and loaded with $\alpha$-arbutin are presented. The loading ability, release profiles, and stability of the nanocarriers at physiologically pertinent conditions, as well as the results of the in vitro investigation subject to nanoparticle interactions with immortalised human skin keratinocyte cells $(\mathrm{HaCaT})$ as regards cytotoxicity and membrane permeability are also discussed.

\section{Materials and Methods}

\subsection{Materials}

Pullulan (Mw $100 \mathrm{kDa}$ ), 2-(butoxymethyl)oxirane (BMO; analytical grade 95\%), $\alpha$ arbutin, sodium hydroxide $(\mathrm{NaOH})$, phosphate-buffered saline (PBS), phosphate-citrate buffer (PCB), Dulbecco's Modified Eagle's Medium (DMEM), Hank's balanced salt solution (HBSS), foetal bovine serum (FBS), rat tail collagen, and trypsin-EDTA were obtained from Sigma-Aldrich Chemie GmbH (Steinheim, Germany). Dimethyl sulfoxide (DMSO; HPLC grade $\geq 99.9 \%$ ), diethyl ether (analytical grade), hydrochloric acid $(\mathrm{HCl}), \mathrm{H}_{2} \mathrm{O}$ (HPLC grade), and methanol (HPLC grade $\geq 99.9 \%$ ), were supplied by Fisher Scientific (Loughborough, UK). 


\subsection{Preparation of Grafted Pullulan (BMO-PUL) Derivatives}

The synthetic method was adapted from the literature [38], as follows: to an aqueous pullulan solution $(0.5 \mathrm{~g} ; 3.05 \mathrm{mmol} ; 45 \mathrm{~mL})$, a solution of sodium hydroxide $(33 \% \mathrm{w} / \mathrm{v}$; $\sim 0.5 \mathrm{~mL}$ ) was incrementally introduced under stirring to alkalinise ( $\mathrm{pH} 14)$ the mixture; the stirring was maintained for $2 \mathrm{~h}$ prior to storage $\left(-20^{\circ} \mathrm{C}\right)$ for 5 days. Following thawing at $25^{\circ} \mathrm{C}$, 2-(butoxymethyl)oxirane $(3.05 \mathrm{mmol}, 0.44 \mathrm{~mL})$ was introduced dropwise under vigorous magnetic stirring (LMS-1003, Daihan Labtech Co., Ltd., Namyangju, Korea) and further agitated at $45^{\circ} \mathrm{C}$ for another $16 \mathrm{~h}$ (under $\mathrm{N}_{2}$ atmosphere); the process was repeated using different concentrations $(15.25 \mathrm{mmol}, 2.18 \mathrm{~mL}$ and $24.40 \mathrm{mmol}, 3.49 \mathrm{~mL}$ and $57.95 \mathrm{mmol}, 8.29 \mathrm{~mL}$ and $91.5 \mathrm{mmol}$, and $13.09 \mathrm{~mL}$ ) to investigate the influence of reagent (BMO) concentration upon the degree of grafting (DG). The mixture was then neutralised by hydrochloric acid $(10 \% v / v)$ and purified by washing with diethyl ether $(\times 3)$ to exclude water-insoluble impurities. The mixture was subsequently purified by dialysis (molecular weight cut-off 12-14 kDa) (10 L ion-free $\mathrm{H}_{2} \mathrm{O} ; 9$ changes over $72 \mathrm{~h}$ ) and lyophilised (VirTis Sentry 2.0, SP Scientific, Genevac Ltd., Ipswich, UK).

\subsection{Characterisation of Grafted Pullulan (BMO-PUL) Derivatives}

Nuclear magnetic resonance (NMR) spectroscopic analysis was carried out by dint of a JEOL Eclipse 400 instrument (JEOL, Welwyn Garden City, UK) running at $400 \mathrm{MHz}$ and $100 \mathrm{MHz}$ for ${ }^{1} \mathrm{H}$ - and ${ }^{13} \mathrm{C}-\mathrm{NMR}$, respectively; the $\mathrm{DG}$ was determined from the ${ }^{1} \mathrm{H}$ NMR spectra. A Nicolet Nexus Euro Fourier-transform infrared (FTIR) spectrometer (Thermo Fisher Scientific, Hemel Hempstead, UK) fitted with a Smart Orbit diamond crystal attenuated total reflectance (ATR) was utilised to record the FTIR spectra (scans $=32$, resolution $=4 \mathrm{~cm}^{-1}$ and wavenumber range $=4000-500 \mathrm{~cm}^{-1}$ ). Thermal analysis methods such as thermogravimetric analysis (TGA) and differential scanning calorimetry (DSC) were done on TG $209 \mathrm{~F} 1 \mathrm{Libra}$ (heating rate $=10 \mathrm{~K} / \mathrm{min}$, temp. range $=25$ to $500{ }^{\circ} \mathrm{C}$, and $\mathrm{N}_{2}$ purge flow rate $=40 \mathrm{~mL} / \mathrm{min}$ ) and DSC 214 Polyma (heating and cooling rate $=10 \mathrm{~K} / \mathrm{min}$, temp. range $=-50$ to $250^{\circ} \mathrm{C}$, and $\mathrm{N}_{2}$ purge flow rate $=40 \mathrm{~mL} / \mathrm{min}$ ) instruments (NETZSCH, Selb, Germany), respectively.

Native and BMO-PUL were investigated for their viscosity by a Gilmont GV-2100 falling-ball viscometer (Gilmont Instruments Inc., Barrington, IL, USA). An aqueous polymer solution $(1 \% w / v)$ was introduced into the viscometer cylindrical tube $(\sim 10 \mathrm{~mL})$ and a glass sphere (density $=2.53 \mathrm{~g} / \mathrm{mL}$ ) was carefully introduced. The elapsed time required for the glass sphere to fall under gravity through the samples was recorded and the viscosity was determined utilising Equation (1) (viscometer constant $=0.3$ and liquid density $=1.0 \mathrm{~g} / \mathrm{mL}$ ):

$$
\eta=K(\rho t-\rho) t
$$

where

$\eta:$ calculated viscosity $(\mathrm{cp})$

$\rho_{\mathrm{t}}$ : ball density $(\mathrm{g} / \mathrm{mL})$

$\rho$ : liquid density $(\mathrm{g} / \mathrm{mL})$

$\mathrm{t}$ : descent time (min)

$\mathrm{K}$ : viscometer

Molecular weights were measured on a Waters Alliance GPC-2000 gel permeation chromatography (Waters Corporation, Milford, MA, USA) fitted with a PL aquagel-OH gel column (8- $\mu \mathrm{m}$ particle size) under controlled temperature $\left(30^{\circ} \mathrm{C}\right)$, with refractive index detection. Eluent system of either $100 \% \mathrm{H}_{2} \mathrm{O}$ or an 8:2 $(v / v) \mathrm{H}_{2} \mathrm{O}$ :DMSO mixture (HPLC grade) was employed (flow rate $=0.5 \mathrm{~mL} / \mathrm{min}$ ). Pullulan standards (Mws 0.6-80.5 $\times 10^{4} \mathrm{~g} / \mathrm{mol}$; Showa Denko, New York, NY, USA) calibration curves were utilised to estimate the molecular weight $(\mathrm{Mw})$ of the grafted pullulan.

\subsection{Formulation of Nanoparticles from Grafted Pullulan (BMO-PUL)}

To ultrapure $\mathrm{H}_{2} \mathrm{O}(8 \mathrm{~mL})$, a solution of BMO-PUL in dimethyl sulfoxide (2 mL) (concentration range 1,5 , and $10 \mathrm{mg} / \mathrm{mL}$ with various $\mathrm{DG}$, as specified) was introduced 
dropwise under constant stirring. The resultant BMO-PUL nanoformulations were dialysed (molecular weight cut-off $12-14 \mathrm{kDa})\left(10 \mathrm{~L}\right.$ ion-free $\mathrm{H}_{2} \mathrm{O}$; 9 changes over $72 \mathrm{~h}$ ) before being collected by freeze-drying (yields $76-83 \%$ ).

\subsection{Physical Characterisation of Grafted Pullulan (BMO-PUL) Nanoparticles}

The critical micellar concentration (CMC) of BMO-PUL amphiphiles and the hydrodynamic diameter of the self-assembled carriers were measured via DLS using a Malvern ZetasizerNano ZS instrument (Malvern Instruments, Malvern, UK; $633 \mathrm{~nm}$ He-Ne laser; back-scattering angle of $173^{\circ}$; Zetasizer v7.01 software). The samples were tested in triplicate $\left(25^{\circ} \mathrm{C}\right)$; the NPs size was reported as the Z-average mean values (Z-av.) together with the dispersity index (DI). Changes in the scattered light intensity whilst varying the sample concentration $(30-70 \mathrm{mg} / \mathrm{L}$ ) were monitored to determine the CMC. The zeta $(\zeta)$ potential of the nanoparticles was figured out by electrophoretic mobility measurements (EPM) on a similar instrument; the results were processed based on Smoluchowski's formula (Henry's function $\mathrm{f}(\mathrm{ka})=1.5)$.

Morphological investigation of the nanoparticles was done with a JEOL-JSM-6060LV (JEOL, Tokyo, Japan) electron scanning microscope (SEM). Sample preparation was done by placing a dispersion of lyophilised nanoparticles in ultrapure $\mathrm{H}_{2} \mathrm{O}(5 \mathrm{mg} / \mathrm{mL})$ onto a metallic stub and dried before being coated with $\mathrm{Au} / \mathrm{Pd}$ (Ar atmosphere) on a Quorum Q150RES sputter coater (Quorum Technologies Ltd., East Sussex, UK).

\subsection{Loading and Release Studies}

The nanoparticle loading capacity was examined utilising $\alpha$-arbutin as a model active following loading into NPs via nanoprecipitation as follows: to a solution of BMO-PUL (DG 33.8\%) in DMSO (2 mL), $\alpha$-arbutin $(0.5 \mathrm{mg})$ was dissolved prior to the dropwise addition into ultrapure $\mathrm{H}_{2} \mathrm{O}(8 \mathrm{~mL})$ under strong stirring. The resultant nanocarriers were centrifuged $\left(164,391 \times \mathrm{g} ; 30 \mathrm{~min} ; 20^{\circ} \mathrm{C}\right)$; the pellets were freeze-dried and collected. A Reversed-Phase (RP) HPLC $(\lambda=222 \mathrm{~nm})$ on a Jasco LC-4000 series HPLC system (Jasco Inc., Easton, MD, USA); C18 RP column, 89:10:1 $(v / v / v) \mathrm{H}_{2} \mathrm{O}: \mathrm{MeOH}: 0.1 \mathrm{M} \mathrm{HCl}$; flow rate $=1 \mathrm{~mL} / \mathrm{min}$; retention time $=5.7 \mathrm{~min}$, and lower detection limit $=25 \mathrm{ng} / \mathrm{mL}$ ) was utilised for the analysis of the supernatant to estimate the free $\alpha$-arbutin quantity. The collected data were plotted against the calibration curves, and the loading (presented as the ratio of drug weight to the total weight of NPs) was estimated utilising Equation (2):

$$
\text { DL }(\%)=\frac{\text { weight of drug }}{\text { weight of nanoparticles }} \times 100
$$

The investigation of $\alpha$-arbutin release was conducted by redispersing the $\alpha$-arbutinloaded BMO-PUL NPs $(2 \mathrm{mg} / \mathrm{mL})$ in either PCB (pH 5) or PBS (pH 7) medium $(4 \mathrm{~mL})$ and placed into Eppendorf tubes before being kept in a shaking water bath (WSB-30, Daihan Labtech Co., Ltd., Korea) under controlled temperature $\left(37^{\circ} \mathrm{C}\right)$. Every Eppendorf tube was removed from the water bath at predetermined time points prior to aliquot withdrawal $(2 \mathrm{~mL})$ from the supernatant. The analysis was performed through RP-HPLC.

\subsection{Stability Studies}

Nanoparticle stability was assessed for 90 days by redispersing $(2 \mathrm{mg} / \mathrm{mL})$ and incubating $\alpha$-arbutin-loaded BMO-PUL (DG 33.8\%) nanoparticles in either PCB (pH 5) or PBS (pH 7) at various temp. (either 4 or $25^{\circ} \mathrm{C}$ ). Any possible changes in the Z-av., ZP, and DI of the nanoparticles were analysed with a Malvern ZetasizerNano ZS.

\subsection{Cell Culture}

Immortalised human keratinocytes (HaCaT) cells were acquired from Cell Lines Service (Eppelheim, Germany). The cells (passage no. 17-25) were cultured (in Corning T25 flasks; media volume $6 \mathrm{~mL}$ ) in DMEM (enriched with $2 \mathrm{mM}$ L-glutamine, $0.1 \mathrm{mg} / \mathrm{mL}$ streptomycin, $100 \mathrm{U} / \mathrm{mL}$ penicillin, and $10 \% v / v$ foetal bovine serum) at $37^{\circ} \mathrm{C}$ in a humidified 
ambiance with $5 \% \mathrm{CO}_{2}$. The detachment of cells was done using trypsin-EDTA, prior to being harvested by centrifugation $(120 \times g ; 5 \mathrm{~min})$ for $5 \mathrm{~min}$.

\subsection{Cytotoxicity Assay}

$\alpha$-arbutin-loaded BMO-PUL NPs suspensions in DMEM (50 $\mu \mathrm{L} ; 0.1-4 \mathrm{mg} / \mathrm{mL})$ were cultured $\left(37^{\circ} \mathrm{C}\right)$ with confluent $\mathrm{HaCaT}$ cells for $24 \mathrm{~h}$ (seeding $\left.5 \times 10^{3}\right)$. The medium was then substituted with MTT (3-(4,5-dimethylthiazol-2-yl)-2,5-diphenyltetrazolium bromide) reagent $(100 \mu \mathrm{L} ; 10 \% w / v)$ and incubated for another $3 \mathrm{~h}$ before being substituted by DMSO $(100 \mu \mathrm{L})$. Initially, the MTT reagent was prepared by dissolving 3-(4,5-dimethylthiazol-2-yl)2,5-diphenyltetrazolium bromide in a serum-free DMEM media $(1 \mathrm{mg} / \mathrm{mL})$. The plate was then analysed on a Multiskan GO microplate reader (Thermo Fisher Scientific, Waltham, MA, USA; measuring at $570 \mathrm{~nm}$ ).

\subsection{Permeability Studies across HaCaT Cell Monolayers}

The test was adapted from a method described in the literature [39] as follows: a modified Transwell-type HaCaT model (Figure 1) was set up by introducing HBSS (200 $\mu \mathrm{L})$, collagen $(100 \mu \mathrm{L} ; 0.4 \%)$, DMEM $(100 \mu \mathrm{L})$, and FBS $(10 \% v / v)$ mixture into a sterile Millipore Millicell 24-well plate (Millipore, Billerica, MA, USA) prior to $30 \mathrm{~min}$ of incubation $\left(5 \% \mathrm{CO}_{2}\right.$; $\left.37^{\circ} \mathrm{C}\right)$. After the collagen gel solidified, a HaCaT cell suspension was planted $\left(5 \times 10^{3}\right.$ cells $)$ and cultivated until confluency. Individual wells were filled with dispersions of $\alpha$-arbutinloaded BMO-PUL nanocarriers $(200 \mu \mathrm{L} ; 4 \mathrm{mg} / \mathrm{mL})$ in DMEM and the $\alpha$-arbutin conc. in the receiver compartment was observed. Aliquots $(100 \mu \mathrm{L})$ were withdrawn every $1 \mathrm{~h}$ from the receiver compartment throughout $5 \mathrm{~h}$ ); they were sonicated $(10 \mathrm{~min}$ ) and ultracentrifuged $\left(164,391 \times g ; 20 \mathrm{~min} ; 25^{\circ} \mathrm{C}\right.$; X3 Beckman, Beckman Coulter, High Wycombe, UK), and the supernatant was then analysed through RP-HPLC. The experiment was repeated using free $\alpha$-arbutin $(200 \mu \mathrm{L} ; 0.5 \mathrm{mg} / \mathrm{mL}$ dissolved in DMEM) for comparison and the apparent permeability coefficient (Papp) was calculated utilising Equation (3):

$$
\operatorname{Papp}\left(\mathrm{cm} \cdot \mathrm{s}^{-1}\right)=\frac{\mathrm{dQ}}{\mathrm{dt}} \times \frac{1}{\mathrm{~A} \times \mathrm{Co}}
$$

where

$\mathrm{dQ} / \mathrm{dt}: \alpha$-arbutin flux translocated via the membrane ( $\mu \mathrm{g} / \mathrm{sec})$,

A: filter surface area $\left(0.33 \mathrm{~cm}^{2}\right)$ and

Co: $\alpha$-arbutin original mass conc. at the donor compartment $\left(100 \mu \mathrm{g} / \mathrm{cm}^{3}\right)$.

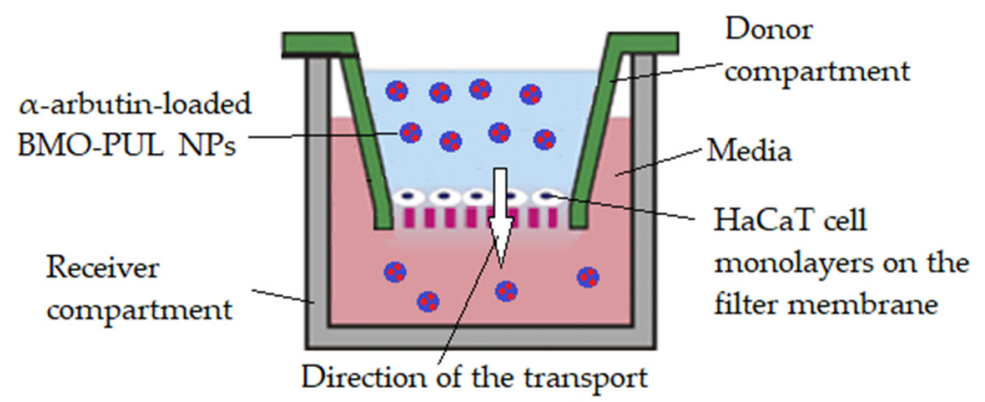

Figure 1. Illustration of the modified Transwell-type HaCaT model employed in these studies.

\subsection{Data Statistical Analysis}

All data were acquired from at least $n=3$ (unless mentioned otherwise) and statistically analysed by SPSS version 22 software (SPSS Inc., Chicago, IL, USA). The statistical significance was calculated using one-way analysis of variance (ANOVA) with a $p \leq 0.05$, unless indicated otherwise. The results were depicted as the mean \pm standard deviation (SD). 


\section{Results and Discussion}

BMO-PUL derivatives of pullulan were prepared by reacting the native polysaccharide with $\mathrm{BMO}$ in an aqueous alkaline solution $(\mathrm{NaOH}, \mathrm{pH} 14$; Figure 2). $\mathrm{NaOH}$ converts the pullulan $\mathrm{OH}$ groups into alcoholates, which react via a nucleophilic substitution with the epoxide ring and, thus, facilitate the grafting of the hydrophobic alkyl chain [2-(butoxymethyl)oxirane] to the polysaccharide chain [38]. According to the literature, the attachment of the hydrophobic alkyl chain is expected to mainly take place at the $\mathrm{C}^{6}$ primary $\mathrm{OH}$ group, owing to its high reactivity and reduced steric hindrance [40-43].
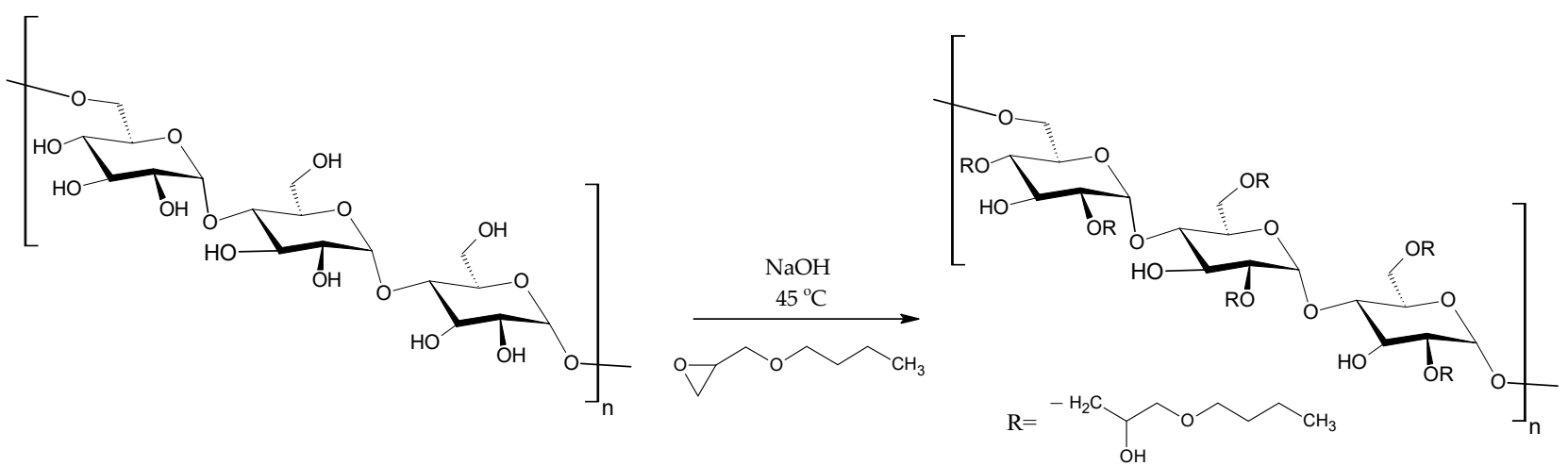

Figure 2. A schematic of the synthesis of grafted pullulan (BMO-PUL).

The lyophilised products were acquired as low-density, white cotton-like materials (yield $81-84 \%$ ), with the chemical modification being verified by ${ }^{1} \mathrm{H}$ - and ${ }^{13} \mathrm{C}-\mathrm{NMR}$, as well as FTIR spectroscopy. The Mw was in the range 100-136 kDa, as analysed by gel permeation chromatography (GPC). In the ${ }^{1} \mathrm{H}-\mathrm{NMR}$ spectra of BMO-PUL (Figure 3a), the peaks of pullulan backbone protons appeared over the spectral range $\delta 3.3-5.4 \mathrm{ppm}$; 3.3-4 ppm assigned to proton signals at $C^{2-6}$, whilst 5-5.4 ppm was assigned to anomeric protons [11]. The signals recorded at $\delta 0.9, \delta 1.3$, and $\delta 1.5 \mathrm{ppm}$ (denoted as peaks 3,2 , and 1 in Figure 3, respectively) were indicative of the existence of the hydrophobic alkyl chain groups [38]; other protons signal assignments are presented in Figure 3a. The ${ }^{13} \mathrm{C}-\mathrm{NMR}$ spectrum concurred with the ${ }^{1} \mathrm{H}-\mathrm{NMR}$ data, with alkyl chain carbons detected at $\delta=14$, $19,31,44,51$, and $71 \mathrm{ppm}$, as displayed in Figure $3 \mathrm{~b}$. The ${ }^{13} \mathrm{C}$-NMR spectrum of the BMO reagent is recorded in Figure S1, Supplementary Materials. Other significant peaks in the ${ }^{13} \mathrm{C}$-NMR spectrum were depicted as follows: $\delta=101-103 \mathrm{ppm}$ for polysaccharide $\mathrm{C}^{1}$, $\delta=68-77 \mathrm{ppm}$ for $\mathrm{C}^{2,3,5}, \delta=80 \mathrm{ppm}$ for $\mathrm{C}^{4}$, and $\delta=61 \mathrm{ppm}$ for $\mathrm{C}^{6}[41]$.

The degree of grafting (DG) was calculated based upon the ratio of the integral values of the alkyl chain end $\mathrm{CH}_{3}$ group $(\delta 0.9 \mathrm{ppm})$ to the glucopyranosic ring sugar protons ( $83.3-4.0 \mathrm{ppm}$ ), as evidenced by the ${ }^{1} \mathrm{H}-\mathrm{NMR}$ spectra. The DG (presented as hydrophobic alkyl chain number grafted to 100 glucopyranose units in the pullulan molecule; i.e., $100 \%=$ all three possible sites in a single sugar residue were completely grafted) of BMOPUL was calculated utilising Equation (4):

$$
\mathrm{DG}[\%]=\frac{2 \mathrm{~A} \times 100}{3 \mathrm{~B}}
$$

where

DG (\%): degree of grafting (hydrophobic alkyl chain number attached to 100 sugar residues),

A: integral of the peak ascribed to the alkyl chain end $\mathrm{CH}_{3}(\delta 0.9 \mathrm{ppm})$.

$\mathrm{B}$ : integral of the signal ascribed to the glucopyranosic ring sugar protons ( $83.3-4.0 \mathrm{ppm})$. 


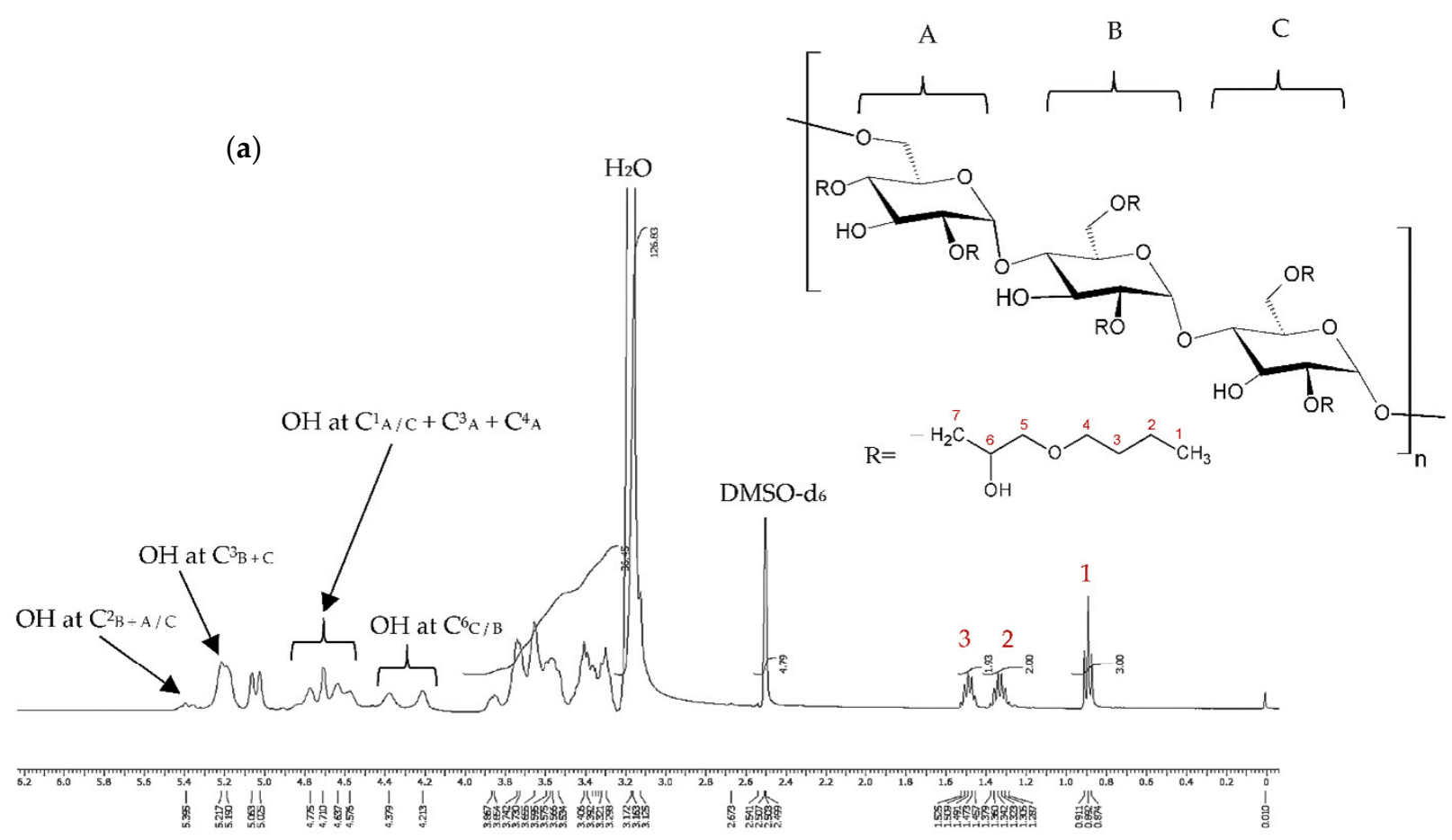

(b)

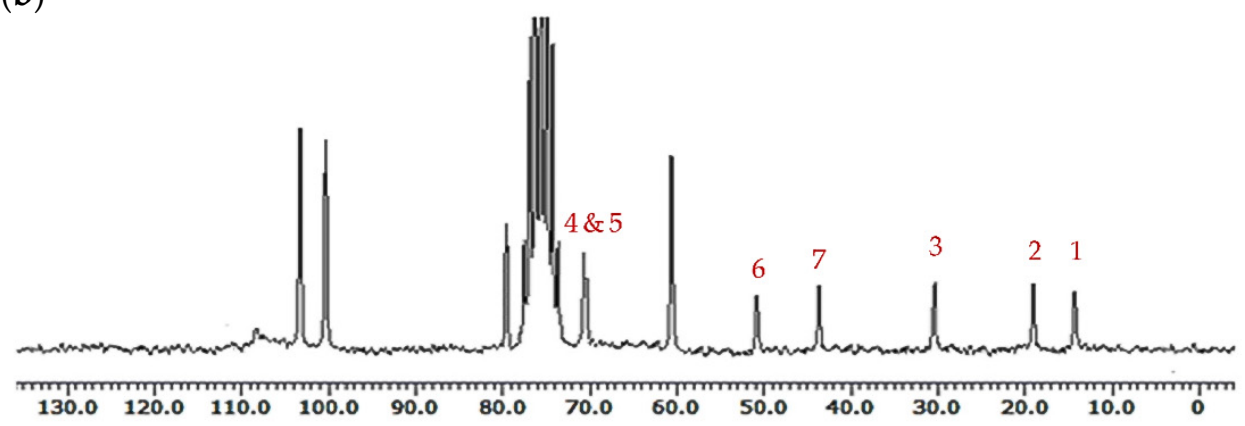

Figure 3. Typical ${ }^{1} \mathrm{H}-\mathrm{NMR}(\mathbf{a})$ and ${ }^{13} \mathrm{C}-\mathrm{NMR}(\mathbf{b})$ spectra of BMO-PUL in DMSO- $\mathrm{d}_{6}(7 \mathrm{mg} / \mathrm{mL})$. The three sugar rings of BMO-PUL were ascribed as A, B, and C.

The effect of BMO reagent conc. on BMO-PUL degree of grafting was also studied; as illustrated in Figure 4, the DG increased together with an increase in the reagent concentration. The calculated DG was almost linearly proportional to the molar ratio $\left(\mathrm{y}=1.98 \mathrm{x}+7.80 ; r^{2}=0.93\right)$, indicating the potential capability of pullulan in taking in greater molar ratios than were employed to afford BMO-PUL with greater DG. The DG of BMO-PUL obtained in this study, however, was found to be lower than that of hydrophobically grafted pullulan synthesised in a nonaqueous environment (DG 47-77\%; potassium tert-butoxide (KOt-Bu) as the catalyst) - albeit using a similar pullulan:BMO molar ratio. This is perhaps owing to the catalyst/base strength used in the reaction; KOt-Bu is considerably powerful than $\mathrm{NaOH}$ and, hence, enhanced the alcoholates reactivity to react with the opened-ring epoxide [44]. Moreover, the presence of $\mathrm{H}_{2} \mathrm{O}$ that may serve as a nucleophile, making itself possible to interfere with the reaction, which may also reduce the reaction rate between the alkylglycerols and pullulan [45]. 


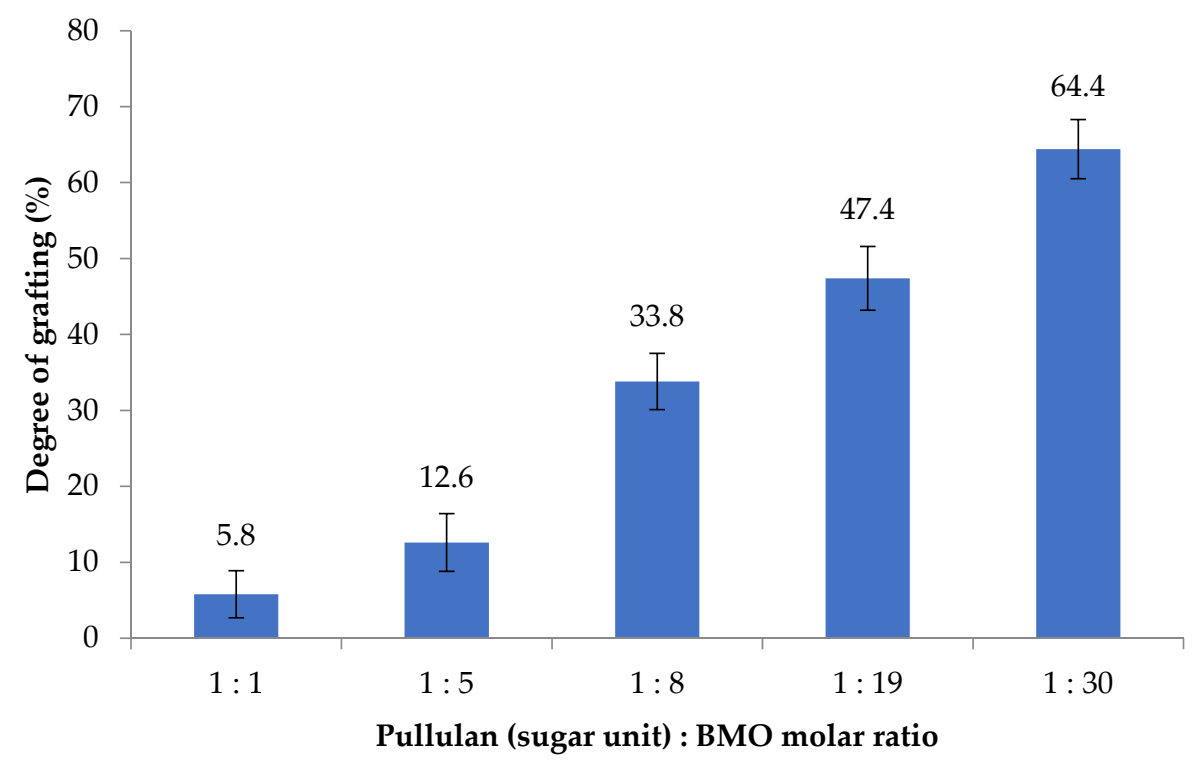

Figure 4 . The effect of reagent ratio on the grafting degree $(n=3 ; \pm \mathrm{SD})$.

As illustrated by the FTIR spectra results (Figure 5), the major bands of native pullulan and BMO-PUL were exhibited and assigned as follows: wide peaks at $3363-3313 \mathrm{~cm}^{-1}$ ascribing $\mathrm{O}-\mathrm{H}$ groups stretching resulting from intra- and intermolecular hydrogen bonding, peaks at $2929-2916 \mathrm{~cm}^{-1}$ ascribing $-\mathrm{CH}_{2}$ asymmetric stretching, and peaks at $1140-1000 \mathrm{~cm}^{-1}$ ascribing $\mathrm{C}-\mathrm{O}-\mathrm{C}$ stretching from glycosidic bonds [46,47]. Functionalisation of pullulan with 2-(butoxymethyl)oxirane (Figure $5 \mathrm{~b}$ ) resulted in the emergence of a new $\mathrm{C}-\mathrm{H}$ peaks (assigned to a $-\mathrm{CH}_{3}$ symmetric stretching vibration at $2864 \mathrm{~cm}^{-1}$ ) and an enhance in the ether $(\mathrm{C}-\mathrm{O}-\mathrm{C})$ band intensity $\left(1140-1000 \mathrm{~cm}^{-1}\right)$ in which, consistent with our previous alkylglycerol modification done on pectin [38]. According to Wang et al., the enhanced peak intensity at ca. $1110 \mathrm{~cm}^{-1}$ is also expected owing to the stretching vibration of the linear fatty ether backbone of the alkyl chain [48]. A typical 2-(butoxymethyl)oxirane with an intact epoxy ring has peaks at ca. $915-760 \mathrm{~cm}^{-1}$, however, based on Figure 5, those regions were found to be relatively unchanged following the modification this could indicate the success of the epoxy ring-opening in the reaction, as well as the complete removal of unreacted reagent in the final product [49].

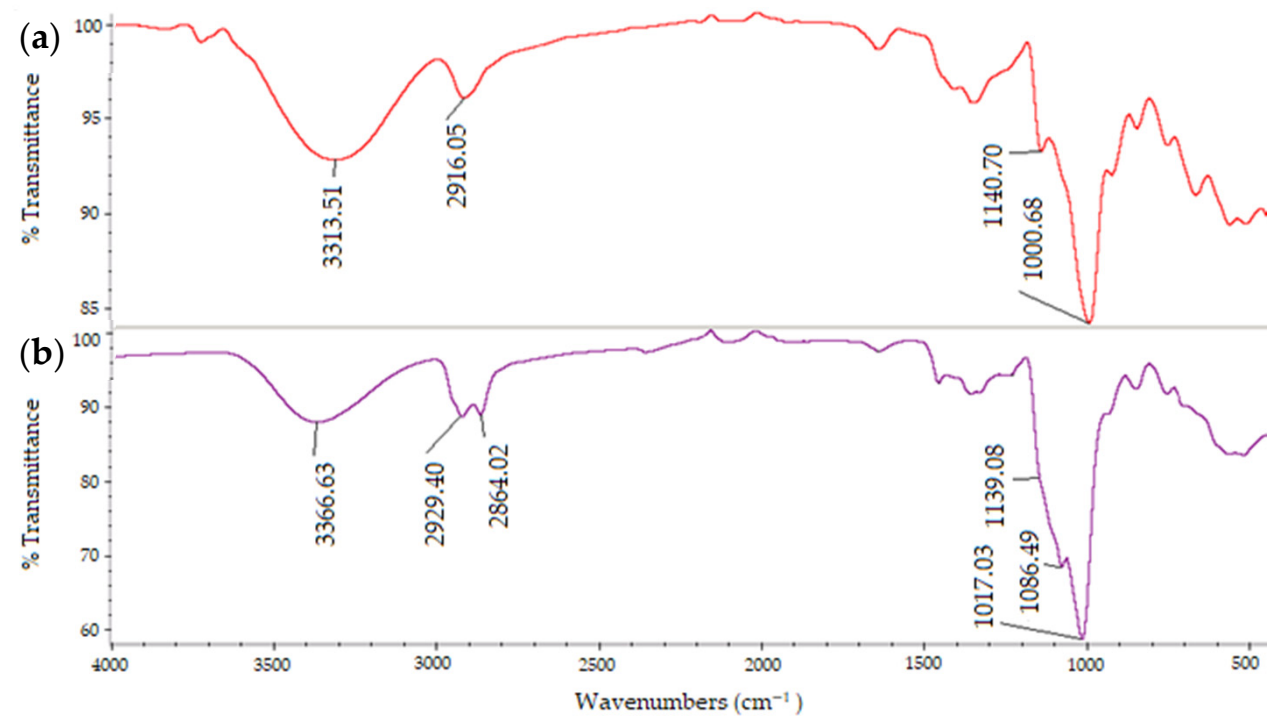

Figure 5. Typical FTIR-ATR spectra of a (a) native pullulan and (b) BMO-PUL. 
Thermal characterisation (TGA and DSC) was conducted to examine the properties, thermal transitions, and stability of the polymers when the temperature was gradually changed; examples of the results obtained are illustrated in Figure 6. The TGA thermogram of BMO-PUL (Figure 6a) showed multiple steps related to different mass loss processes. The initial mass loss step is attributed to evaporating the moisture entrapped in the materials, whereas the second step is ascribed to the thermal decomposition of the materials [50].

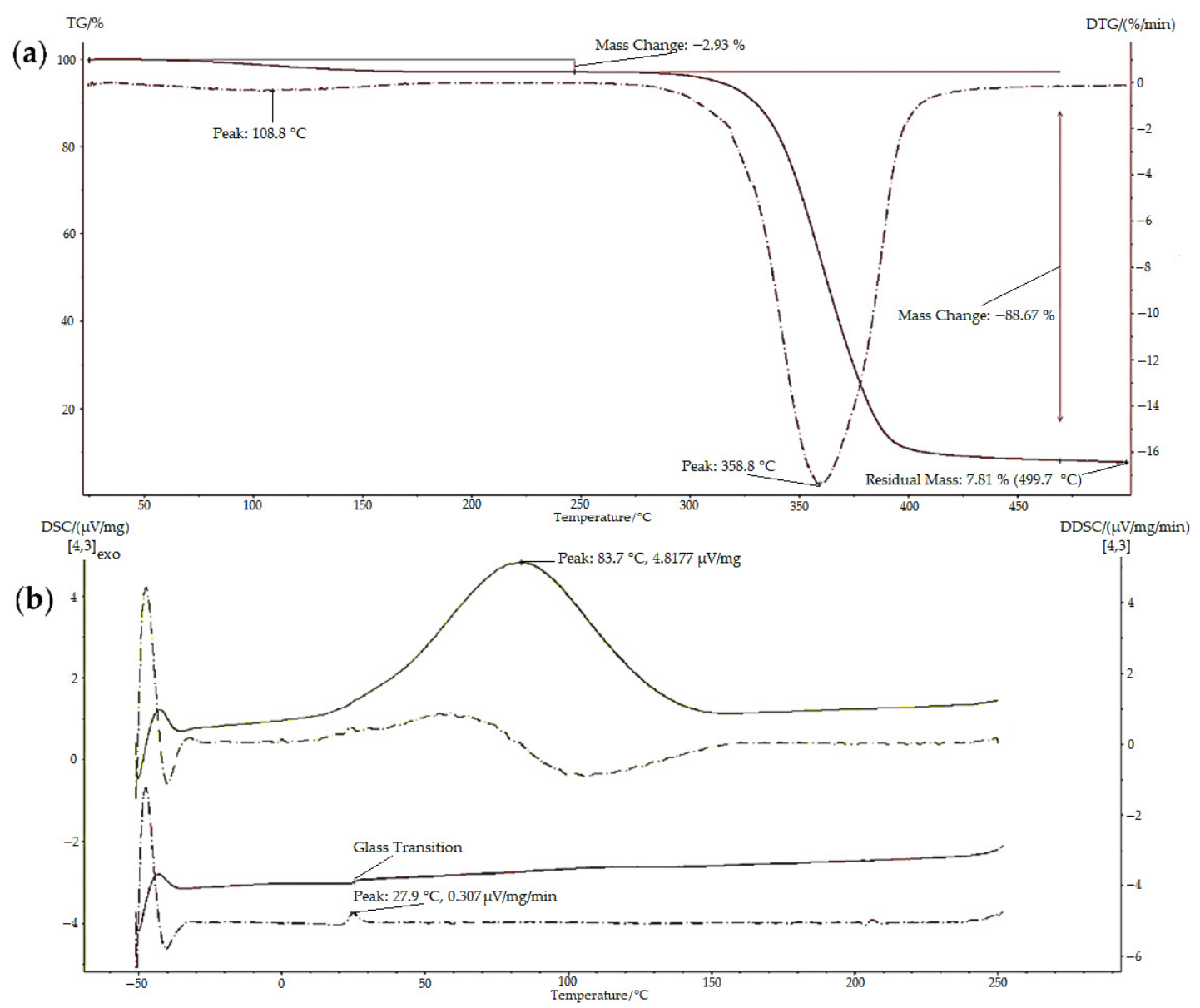

Figure 6. Representative thermal analysis results for BMO-PUL: (a) TGA thermogram: 1st derivative TG (DTG) depicted as a dotted line and (b) DSC curves (top: 1st run and bottom: 2nd run).

Table 1 shows thermal analysis data attained for some samples, and the results affirm the expected increase in the hydrophobicity of the polysaccharide following the functionalisation with 2-(butoxymethyl)oxirane. The measured $\mathrm{H}_{2} \mathrm{O}$ content was found to be inversely proportional to the DG (native pullulan possessed more $\mathrm{H}_{2} \mathrm{O},>6 \%$, compared to the BMO-PUL with values in the range 3-5\%). Lower hydrogen-bonded $\mathrm{H}_{2} \mathrm{O}$ molecules in BMO-PUL derivatives may be attributed to enhanced hydrophobicity after the modification, which ultimately limits them from retaining additional moisture. This is in line with earlier studies on the alkylation of polysaccharides (dextran and pectin) with short-chain alkylglycerols $[31,38]$. BMO-PUL showed increased thermal stability compared to the native, as evidenced by the DTG peak corresponding to the decomposition of the BMO-PUL derivatives that surfaced at a greater temperature. 
Table 1. A summary of the thermal analysis results for BMO-PUL derivatives with different degrees of substitution $(n=3 ; \pm \mathrm{SD})$.

\begin{tabular}{|c|c|c|c|c|c|}
\hline \multirow{2}{*}{ Material (DG \%) } & \multicolumn{2}{|c|}{$\mathrm{H}_{2} \mathrm{O}$ Evaporation } & \multicolumn{2}{|c|}{ Decomposition } & \multirow{2}{*}{$\operatorname{Tg}\left({ }^{\circ} \mathrm{C}\right)$} \\
\hline & DTG Peak $\left({ }^{\circ} \mathrm{C}\right)$ & Mass Loss (\%) & DTG Peak $\left({ }^{\circ} \mathrm{C}\right)$ & Mass Loss (\%) & \\
\hline Native pullulan & $80.9 \pm 4.4$ & $6.52 \pm 1.9$ & $288.5 \pm 3.2$ & $77.17 \pm 6.8$ & $21.3 \pm 0.8$ \\
\hline BMO-PUL (5.8\%) & $102.3 \pm 4.8$ & $5.32 \pm 1.4$ & $340.5 \pm 4.9$ & $78.02 \pm 4.1$ & $24.9 \pm 0.7$ \\
\hline BMO-PUL (12.6\%) & $104.5 \pm 7.7$ & $3.59 \pm 0.9$ & $349.2 \pm 5.2$ & $85.50 \pm 5.9$ & $26.7 \pm 1.1$ \\
\hline BMO-PUL (33.8\%) & $108.8 \pm 5.1$ & $2.93 \pm 1.0$ & $358.8 \pm 3.6$ & $88.67 \pm 7.8$ & $30.1 \pm 1.2$ \\
\hline
\end{tabular}

The polysaccharide glass transition temperature ( $\mathrm{Tg}$ ) moved to higher temperatures following the modification. The introduction of the hydrophobic alkyl chain increased the molecular structure bulkiness of the polysaccharide and led to a reduction in mobility. The alteration in BMO-PUL hydrophobicity results in the removal of hydrogen-bonded $\mathrm{H}_{2} \mathrm{O}$ molecules, which can serve as a plasticiser to increase polymer chain mobility and reduce intermolecular forces, leading to a lower $\mathrm{Tg}$ value of amorphous solids, such as the native pullulan (Table 1) [51,52]. The Tg values of pullulan discussed in the literature differ noticeably. Bizot et al. studied the Tg of pullulan and found that the value varies from 10 to $25^{\circ} \mathrm{C}$ [53]. As Tg values are affected by the composition of each sample, hence, the differences recorded are attributed to batch-to-batch variations that exist in terms of composition, molecular weight, and $\mathrm{H}_{2} \mathrm{O}$ content [54].

Gel permeation chromatography was utilised to study the Mw of pullulan following the modification, and it has been found that functionalisation with 2-(butoxymethyl)oxirane to afford hydrophobically grafted BMO-PUL yielded in an enhance in the Mw (Table 2), which validates the successful attachment of the hydrophobic alkyl chain to the pullulan backbone. Dispersity index (DI) values that are close to one suggested a narrowly dispersed polymer distribution and homogenous branching. GPC chromatogram of BMO-PUL is exemplified in Figure 7.

Table 2. Estimated Mw of the BMO-PUL derivatives $(n=3 ; \pm \mathrm{SD})$.

\begin{tabular}{cccc}
\hline Material & Mn \pm SD & Mw \pm SD & DI \pm SD \\
\hline PUL (Mw 100 kDa) & $77,121 \pm 828$ & $101,191 \pm 923$ & $1.31 \pm 1.11$ \\
BMO-PUL (DG 12.6\%) & $86,236 \pm 970$ & $117,007 \pm 911$ & $1.36 \pm 0.94$ \\
BMO-PUL (DG 33.8\%) & $99,991 \pm 829$ & $136,526 \pm 931$ & $1.37 \pm 1.12$ \\
\hline
\end{tabular}

Investigation on the viscosity of pullulan biopolymer following modification was done, and the results are exemplified in Table 3. A decrease in the BMO-PUL viscosity was observed when compared to that of native pullulan. The presence of free hydroxyl groups has been linked to swelling capacity; therefore, the attachment of the hydrophobic chain onto the pullulan backbone has reduced the presence of free hydroxyl groups, resulting in a decrease in the polymer aqueous viscosity [55]. This is in line with the findings of Lapčík Jr. et al. in their study on hyaluronic acid alkylation utilising various alkyl chain lengths [56,57]. 
(a)
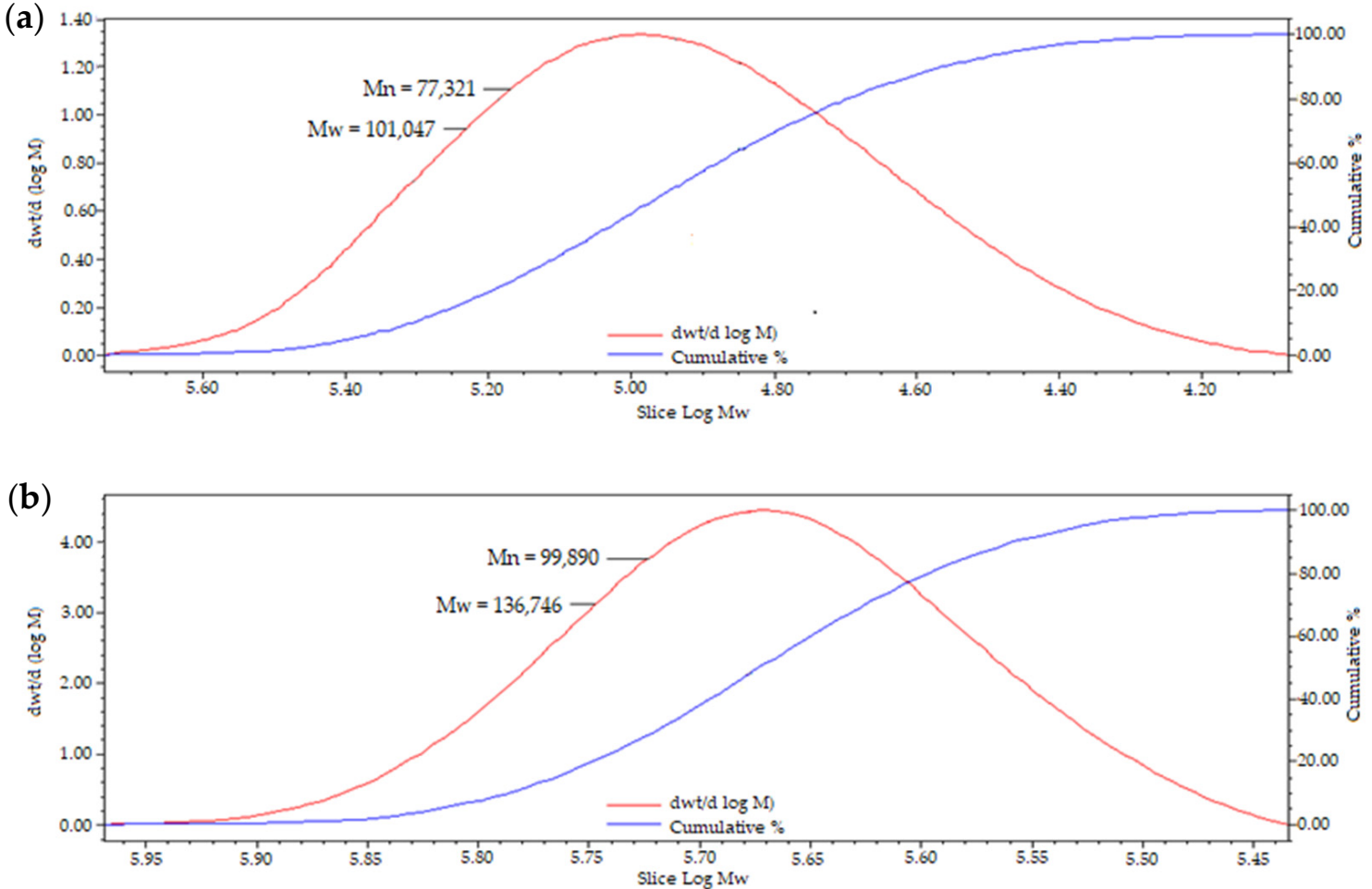

Figure 7. Representative GPC chromatogram of (a) native pullulan and (b) BMO-PUL (DG 33.8\%).

Table 3. BMO-PUL derivatives viscosity data $(n=3 ; \pm \mathrm{SD})$.

\begin{tabular}{cc}
\hline Material & Viscosity $\boldsymbol{\eta}$ (cp) \\
\hline Pullulan & $1.82 \pm 0.1$ \\
BMO-PUL (DG 12.6\%) & $1.58 \pm 0.1$ \\
BMO-PUL (DG 33.8\%) & $1.41 \pm 0.1$ \\
\hline
\end{tabular}

A nanoprecipitation technique was utilised to formulate nanocarriers from BMO-PUL with varying DG and concentrations. The characteristics of the formulated nanoparticles are illustrated in Table 4; the diameter of the nanoformulations determined by DLS was in the range $125-185 \mathrm{~nm}$, with DI values around 0.2 and negative $\zeta$ potentials ranged from -23 to $-34 \mathrm{mV}$ (recommending stable and narrowly dispersed nanoparticles) in agreement with the literature on the formulation of nanocarriers prepared from hydrophobically grafted pullulan acetate via nanoprecipitation, having the Z-av. less than $200 \mathrm{~nm}$ with negative $\zeta$ potential values [58]. The influence of the polymer concentration with varying DG used in the preparation of the nanoparticles was investigated, and an increase in the hydrodynamic diameter of the nanoparticles was observed to be directly proportional to the polymer concentration. However, an inverse proportion between the hydrodynamic diameter and the DG of BMO-PUL was recorded, which is parallel with the results discussed in the literature on the formulation of nanoparticles from amphiphilically modified pullulan [21,22]. 
Table 4. BMO-PUL nanoformulation characteristics at various conc. and DG ( $n=3 ; \pm \mathrm{SD})$.

\begin{tabular}{ccccc}
\hline DG (\%) & Polymer Conc. $\mathbf{( m g / m L )}$ & Diameter $(\mathbf{n m})$ & DI & $\zeta$ Potential $(\mathbf{m V})$ \\
\hline 12.6 & 1 & $143 \pm 12$ & $0.18 \pm 0.07$ & $-25.5 \pm 3.0$ \\
& 5 & $155 \pm 16$ & $0.17 \pm 0.09$ & $-23.3 \pm 2.3$ \\
33.8 & 10 & $182 \pm 18$ & $0.12 \pm 0.06$ & $-28.9 \pm 4.1$ \\
& 1 & $136 \pm 15$ & $0.19 \pm 0.05$ & $-25.7 \pm 1.9$ \\
47.4 & 5 & $145 \pm 19$ & $0.12 \pm 0.11$ & $-23.7 \pm 2.3$ \\
& 10 & $173 \pm 18$ & $0.13 \pm 0.09$ & $-34.2 \pm 4.2$ \\
& 1 & $125 \pm 13$ & $0.14 \pm 0.11$ & $-26.7 \pm 5.2$ \\
& 10 & $139 \pm 12$ & $0.18 \pm 0.04$ & $-28.6 \pm 3.2$ \\
\hline
\end{tabular}

To investigate the CMC, a BMO-PUL aq. solution of varying concentrations ( $30-70 \mathrm{mg} / \mathrm{L})$ in deionised $\mathrm{H}_{2} \mathrm{O}$ was prepared, and the analysis was performed following the methods described in the literature [59]. The scattered light intensity values as a function of BMOPUL conc. are presented in Figure 8. Below the CMC, the scattering intensity values were approximately constant owing to that of deionised $\mathrm{H}_{2} \mathrm{O}$. However, as the conc. increased above the $\mathrm{CMC}$, a significant increase in the scattered light intensity, along with the nanoparticles/micelles size, owing to the augmentation of micelle formation, was observed, yielding the approximate CMC values of $60 \mathrm{mg} / \mathrm{L}$ and $40 \mathrm{mg} / \mathrm{L}$ for BMO-PUL with DG of $12.6 \%$ (Figure 8a) and $33.8 \%$ (Figure 8 b), respectively. The values obtained in this study were found to be relatively consistent with the value reported by Chen et al. for an amphiphilic pullulan derivative [47]. Having low CMC values has been reported to lead to several advantages, including lower toxicity and greater micelles stability. Moreover, it has been noticed that the $\mathrm{CMC}$ values were also found to be inversely proportional to the $\mathrm{Mw}$ and the DG of BMO-PUL, as per the data reported in the literature [59].
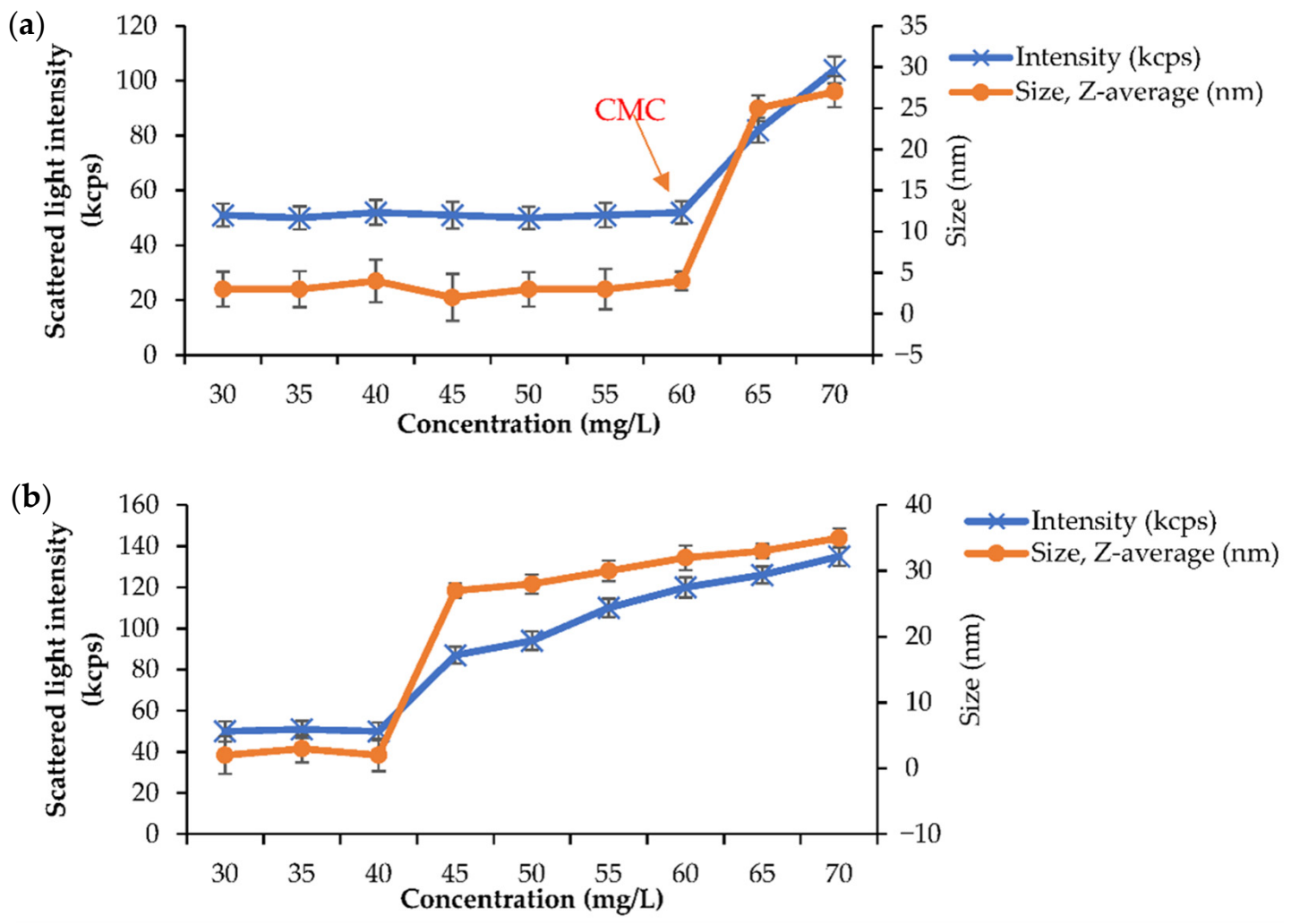

Figure 8. Scattering light intensity as a function of the concentration (range 30-70 mg/L) for BMO-PUL derivatives with different DG: (a) $12.6 \%$ and (b) $33.8 \%(n=3$; \pm SD). 
Microscopy investigation of the nanocarriers was performed by SEM, and a typical micrograph is illustrated in Figure 9, showing that the nanocarriers with submicron diameters exhibit close-to-spherical morphology, similar to the results described by Lee et al. [58]. A closely packed arrangement of BMO-PUL nanoparticles observed in the SEM image is attributed to the drying process during sample preparation [21].

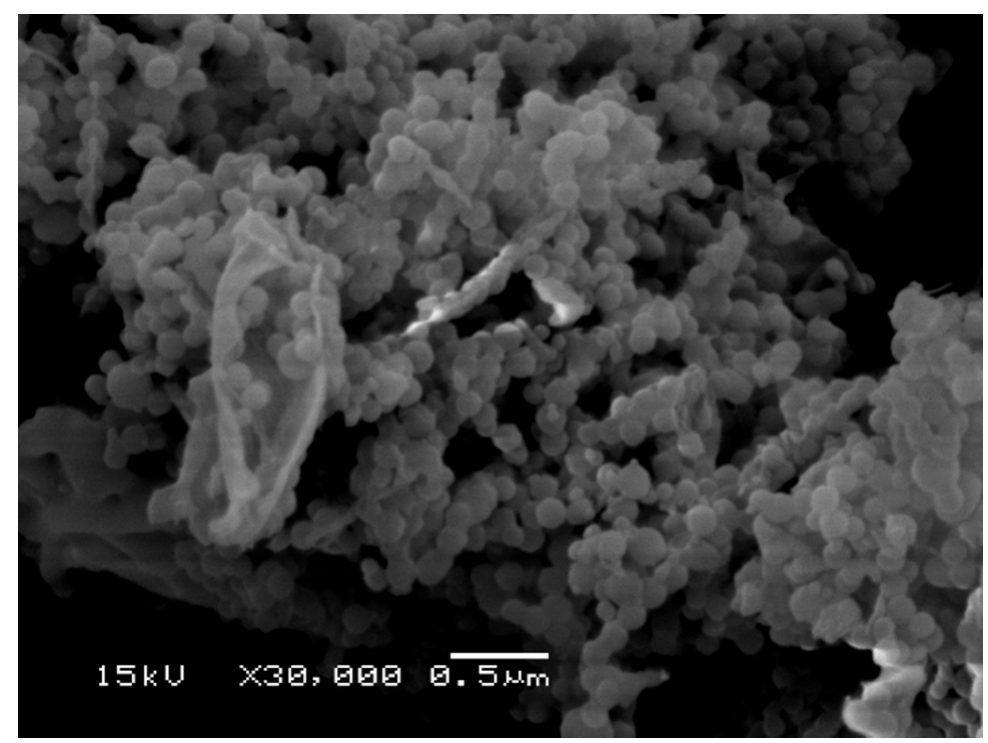

Figure 9. SEM micrograph of lyophilised BMO-PUL nanoparticles (Bar: $0.5 \mu \mathrm{m}$ ).

In general, nanoparticles formulated from hydrophobically grafted materials have been more widely investigated with hydrophobic drugs, where high loading degree values (DL) have been reported compared to hydrophilic solutes [60-62]. In our study, a small water-soluble whitening agent, $\alpha$-arbutin $(\mathrm{Mw} \sim 272 \mathrm{Da}, \log \mathrm{P}-1.49)$ [63], that is known to possess inadequate skin permeability was utilised as a model therapeutic to explore the loading ability and release profiles of BMO-PUL nanoparticles [33,34]. $\alpha$-arbutin was loaded by formulation via nanoprecipitation, and the DL (as determined by RP-HPLC) was calculated utilising Equation (2); values of $16.1 \pm 2.2 \%$ were obtained.

Rationalised by the fact that skin $\mathrm{pH}$ ranges between 4 and $7, \alpha$-arbutin released profiles were investigated in two different buffers, namely phosphate-citrate buffer (PCB, $\mathrm{pH}$ 5) and phosphate-buffered saline (PBS, pH 7) [64]. A similar pattern can be witnessed in both buffered solutions: a relatively fast discharge in the initial stage $(0-2 \mathrm{~h})$, continued by an incremental discharge for the following several hours (Figure 10a). This may be described by an initial discharge of adsorbed $\alpha$-arbutin on the nanocarriers surface, prior to that entrapped within the matrix. A slightly faster release of $\alpha$-arbutin was observed in mildly acidic buffer (PCB) compared to that of neutral $\mathrm{pH}$ (PBS), as shown from the slope of the line following linear regression (Figure 10b). This is likely due to fact that $\alpha$-arbutin is a weak base ( $\mathrm{pKa} \sim 10$ ) that ionises more readily at acidic $\mathrm{pH}$ as compared to neutral, which facilitates its dissolution and release from the matrix of nanoparticles [65]. 

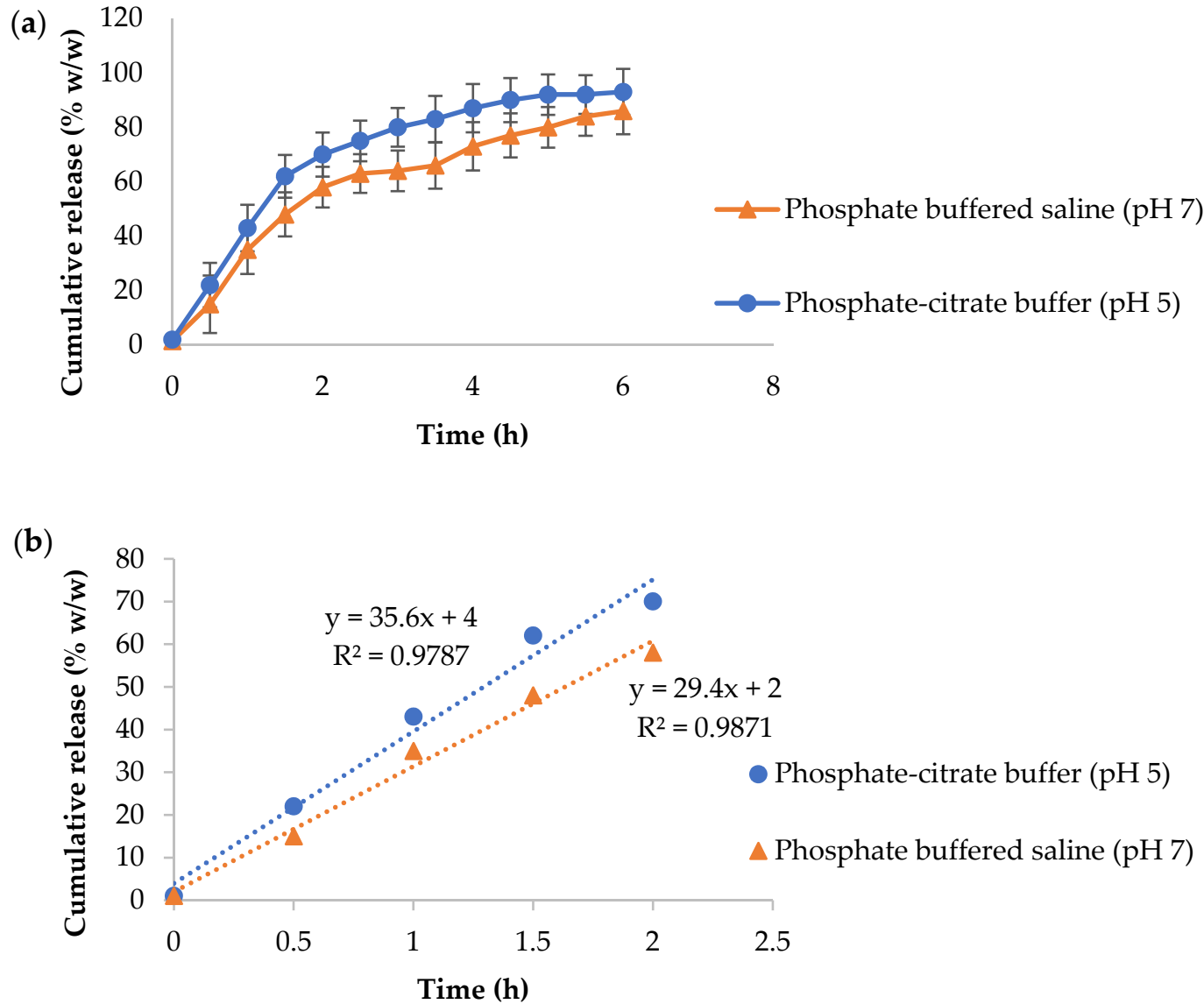

Figure 10. (a) Release profiles (0-6 h) and (b) linear regression profiles $(0-2 \mathrm{~h})$ of $\alpha$-arbutin release from BMO-PUL nanocarriers $(2 \mathrm{mg} / \mathrm{mL}$ ) in either phosphate-citrate buffer $(\mathrm{pH} 5)$ or phosphate-buffered saline ( $\mathrm{pH} 7)$ medium $(n=3 ; \pm \mathrm{SD})$.

The data on drug release were fitted to known kinetic models (such as zero-order, first-order, Higuchi, Korsmeyer-Peppas, and Hixson-Crowell), and the $\mathrm{R}^{2}$ (squared correlation coefficient) values are summarised in Table 5. From the findings, the release of $\alpha$-arbutin can be best described by a first-order model, with the rate being concentrationdependent [66]. The following is a quick overview of the other kinetic models that were tested: the Higuchi model describes drug release from insoluble and porous matrix based on Fickian diffusion. Korsmeyer-Peppas discusses simultaneous drug release processes from a polymeric structure, such as matrix dissolution and swelling. The Hixson-Crowell model depicts drug release from a system with a change in the particle or tablet surface area and diameter. Zero-order defines a system in which drug release is constant and independent of the concentration [67-70].

Table 5. Quality of the fit (expressed as squared correlation coefficient, $\mathrm{R}^{2}$ ) for different kinetic models describing the release of $\alpha$-arbutin from BMO-PUL nanoparticles.

\begin{tabular}{cccccc}
\hline pH Medium & Zero-Order & First-Order & Higuchi & Korsmeyer-Peppas & Hixson-Crowell \\
\hline 5 & 0.7986 & 0.9804 & 0.9489 & 0.3864 & 0.9384 \\
7 & 0.8746 & 0.9829 & 0.9737 & 0.45 & 0.9641 \\
\hline
\end{tabular}

The prospect of using nanoformulations as drug delivery vehicles is strongly linked to their size stability, which may impact their cytotoxicity and efficiency [71]. BMO-PUL nanoformulations were therefore examined for their stability at two $\mathrm{pH}$ values, phosphatecitrate buffer ( $\mathrm{pH} \mathrm{5)}$ and phosphate-buffered saline ( $\mathrm{pH}$ 7), at either 4 or $25^{\circ} \mathrm{C}$. Any possible changes in the nanoparticles diameter over 90 days were monitored, and the results are illustrated in Figure 11. Although the size continued to remain below $200 \mathrm{~nm}$ 
over the whole duration of the studies, incubation at $25^{\circ} \mathrm{C}$ in both buffers witnessed a high increase in the nanoparticle diameters. In general, incubation at $4{ }^{\circ} \mathrm{C}$ induced only a small variation in the diameter, with almost no noticeable change, as was observed when incubated in PCB (indicating good stability, as evidenced by their $\zeta$ potentials in Table 4 ), as opposed to that of PBS. A high temperature is capable of increasing the kinetic movements of nanoparticles, which will ultimately promote collisions between them, which would increase their possibility to form bigger aggregates by van der Waals forces [72].

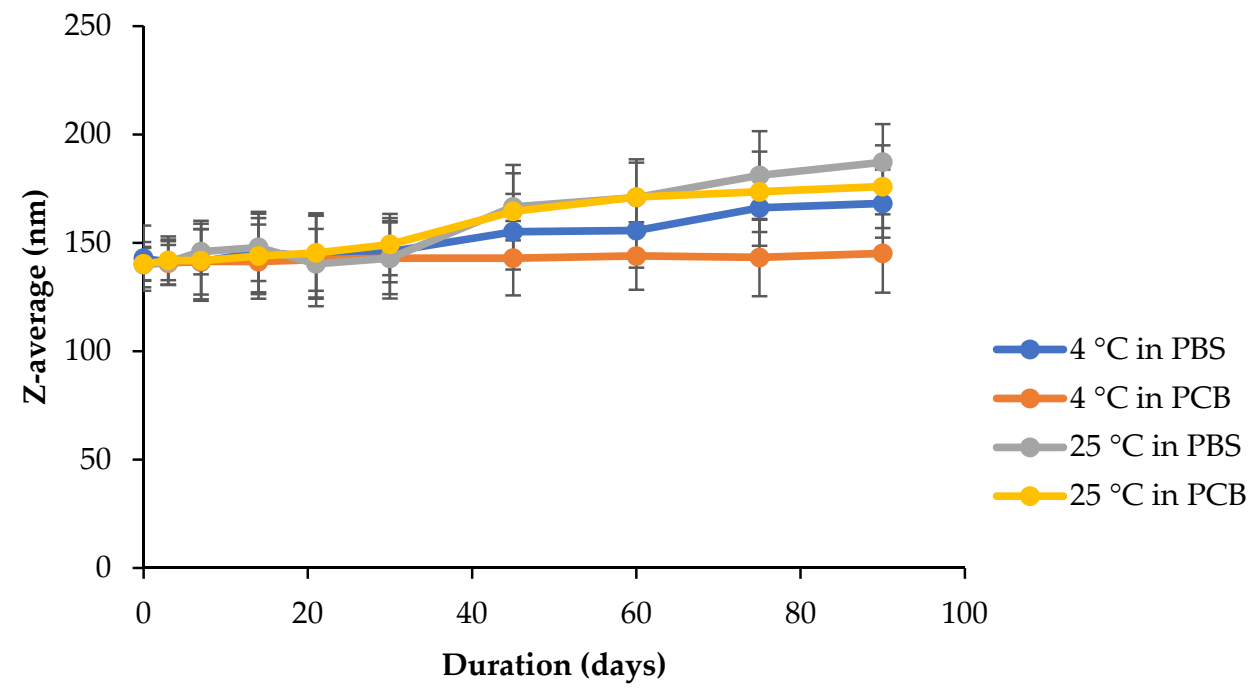

Figure 11. Hydrodynamic diameter of $\alpha$-arbutin-loaded BMO-PUL NPs dispersed $(2 \mathrm{mg} / \mathrm{mL})$ in either phosphate-citrate buffer $(\mathrm{pH} 5)$ or phosphate-buffered saline $(\mathrm{pH} 7)$ at varying temperatures $(4$ or $\left.25^{\circ} \mathrm{C}\right)$ for 90 days $(n=3 ; \pm \mathrm{SD})$.

The lack of cytotoxicity of the $\alpha$-arbutin-loaded nanoparticles was evaluated in vitro at varying concentrations on $\mathrm{HaCaT}$ cells utilising an MTT assay (Figure 12). From the data (Figure 13), an increase in conc. did not initiate a significant reduction in cell viability (with more than $85 \%$ cell viability over the whole concentration range) following incubation for $24 \mathrm{~h}$. This is in line with earlier findings that reported the lack of toxicity for nanoparticles formulated from hydrophobically grafted polysaccharides with short-chain alkylglycerols in various drug delivery applications $[21,31]$.

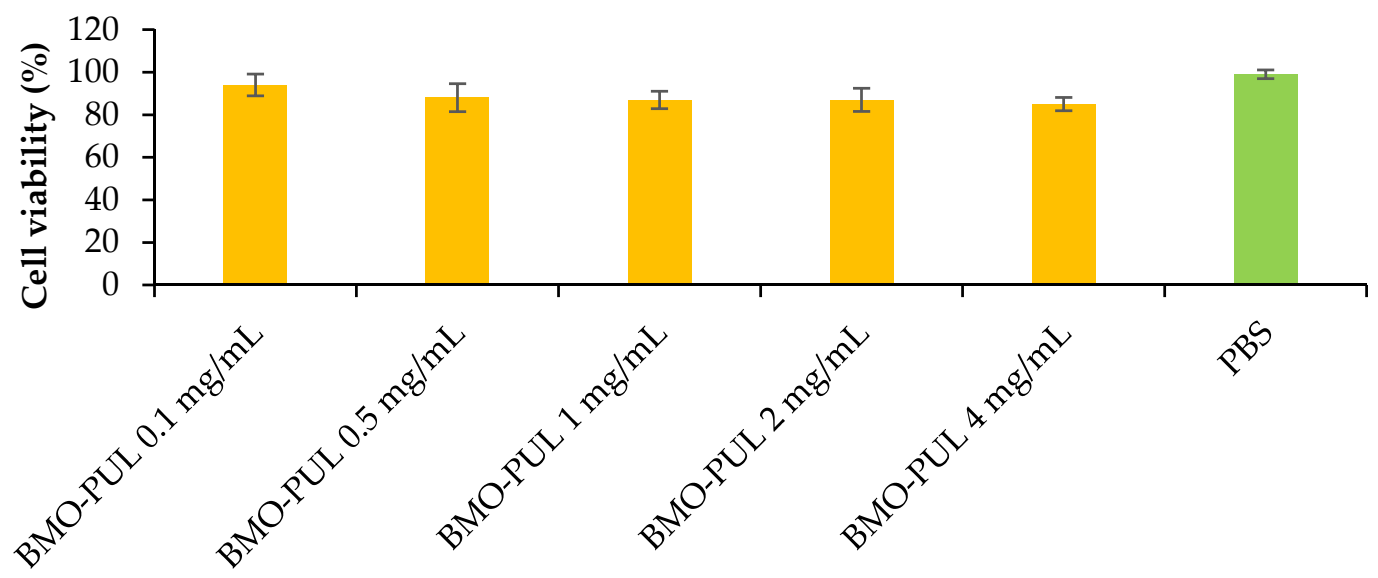

\section{Material}

Figure 12. HaCaT cell viability data for $\alpha$-arbutin-loaded BMO-PUL (concentration range $0.1-4 \mathrm{mg} / \mathrm{mL}$ ) for $24 \mathrm{~h}$ (MTT assay; PBS as a control; $n=3 ; \pm \mathrm{SD}$ ). 


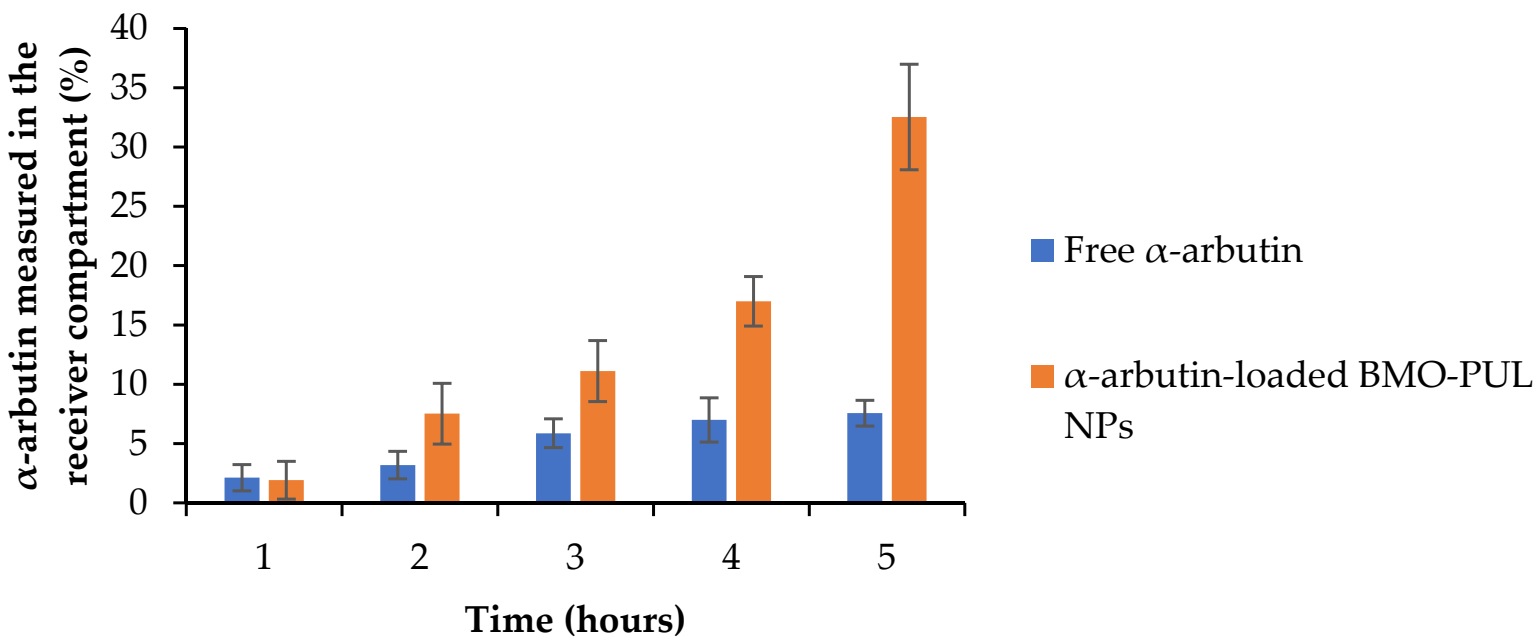

Figure 13. $\alpha$-arbutin translocation (either as free model active or loaded within BMO-PUL NPs) across HaCaT cell monolayers $(n=5, \pm \mathrm{SD})$.

Studies of the ability of BMO-PUL nanocarriers to increase the drug permeations through the $\mathrm{HaCaT}$ cell monolayers were done employing a modified Transwell model system. This system represents a reliable model for the permeability testing of percutaneous preparations, as it simulates the structure and stratification of normal human skin [39,73]. The concentration of loaded BMO-PUL NPs was calculated as equivalent to $0.1 \mathrm{mg}$ of free $\alpha$-arbutin. The results of the translocation of $\alpha$-arbutin either as a free form or loaded within the NPs (Figure 13) showed after $5 \mathrm{~h}$ a four-fold increase in the $\alpha$-arbutin amount transported as a nanoformulation compared to free $\alpha$-arbutin.

The calculated permeability coefficients $\left(\mathrm{P}_{\mathrm{app}}\right)$ are presented in Table 6 and illustrate clearly a significantly higher translocation of $\alpha$-arbutin across the membrane model when loaded within BMO-PUL NPs. The $\mathrm{P}_{\text {app }}$ values reported here were notably higher than those appearing in the literature, using a similar membrane model for FITC-dextran ( $\mathrm{Mw}$ $\sim 40 \mathrm{kDa}$ ), a high molecular weight hydrophilic solute (permeability coefficients of about $\left.0.25-2.4 \times 10^{-8}\right)$, likely due to a significant difference in their molecular weight ( $\alpha$-arbutin $\mathrm{Mw} \sim 272 \mathrm{Da}$ ) [39]. The results presented in this work were considerably higher than earlier studies that investigated the permeation-enhancing effect of hydrophobically grafted guar gum nanocarriers (using the same Transwell-type HaCaT model), with only a two-fold increase in arbutin permeation reported [74]. This might be owing to the smaller size of the nanocarriers and the higher degree of grafting reported in this work. The increased permeation observed is not a result of any subsidiary toxicity to cells, as no significant cytotoxicity was observed (even at $4 \mathrm{mg} / \mathrm{mL}$ ) in the results of the MTT assay (Figure 12; $\geq 85 \%$ of the cells are alive following $24 \mathrm{~h}$ of incubation with BMO-PUL NPs). Although the precise mechanisms have not been completely clarified, it can be presumed that these hydrophobically grafted materials may loosen the lipid tight packing and decrease the barrier resistance, leading eventually to enhanced permeation of solutes across the skin [75].

Table 6. Experimental permeability coefficients $\left(\mathrm{P}_{\mathrm{app}}\right)$ of BMO-PUL nanoparticles through HaCaT cell monolayers at $5 \mathrm{~h}$ incubation time $(n=5 ; \pm \mathrm{SD})$.

\begin{tabular}{cc}
\hline Material & $\left.\mathbf{P}_{\text {app }} \mathbf{5} \mathbf{~ h} \mathbf{( c m} / \mathbf{s}\right)$ \\
\hline Free $\alpha$-arbutin & $(1.29 \pm 0.26) \times 10^{-6}$ \\
$\alpha$-arbutin-loaded BMO-PUL NPs & $(5.55 \pm 0.14) \times 10^{-6}$ \\
\hline
\end{tabular}

\section{Future Directions and Limitations}

With encouraging results obtained in the in vitro studies presented, future works need to concentrate on in vivo models, with several techniques such as micro-dialysis and 
tape stripping $[76,77]$ outlined. These in vivo studies would offer the benefit of using a physiologically and metabolically active system; however, the necessity for radiolabelled material to allow accurate results and the difficulty in detecting the early absorption phase might represent significant limitations. Both animal and human skin can be used, with the latter preferred to minimise cross-species extrapolation; however, there are substantial ethical implications. The Organisation for Economic Cooperation and Development (OECD) guideline no. 428 addressed the standard principles for testing substances in vivo, such as the correct application of the test material, detection and quantification, etc. [78] Although rat skin is most commonly used, absorption tends to be overestimated due to its greater permeability compared to human skin. Other species such as pigs and monkeys may be closer to human absorption, but the costs are far greater [79].

\section{Conclusions}

Hydrophobically grafted pullulan (BMO-PUL) derivatives were successfully synthesised (DG 5-64\%) under aq. alkaline conditions and subsequently formulated into narrowly dispersed nanoparticles (125-185 nm size) via nanoprecipitation. The prepared nanoparticles showed good colloidal stability at $\mathrm{pH} 5$ and 7, with an $\alpha$-arbutin loading degree of around $16 \%$. A slightly faster $\alpha$-arbutin release was observed under acidic conditions (compared to neutral $\mathrm{pH}$ ), and the release profiles can be best described by a first-order model. No significant toxicity against the $\mathrm{HaCaT}$ cells was observed following incubation for $24 \mathrm{~h}$ with varying concentrations of BMO-PUL nanoparticles $(0.1-4 \mathrm{mg} / \mathrm{mL})$, and the translocation of $\alpha$-arbutin through $\mathrm{HaCaT}$ cell monolayers was enhanced four-fold when the active was nanoformulated with BMO-PUL. Overall, the results indicated that BMO-PUL nanocarriers have adequate properties that would justify further research and optimisation of their potential for use in percutaneous drug delivery applications.

Supplementary Materials: The following is available online at https:/ /www.mdpi.com/article/10 .3390 / polym13172852/s1, Figure S1: ${ }^{13}$ C-NMR spectrum of 2-(butoxymethyl)oxirane.

Author Contributions: Conceptualization, M.F.B., E.B. and K.B.L.; methodology, M.F.B.; validation, E.B., K.B.L. and M.F.B.; formal analysis, M.F.B.; investigation, M.F.B.; resources, E.B. and K.B.L.; data curation, M.F.B. and K.B.L.; writing—original draft preparation, M.F.B.; writing—review and editing, E.B. and K.B.L.; visualization, M.F.B.; supervision, E.B.; project administration, M.F.B.; and funding acquisition, M.F.B. All authors have read and agreed to the published version of the manuscript.

Funding: This research was funded by MAJLIS AMANAH RAKYAT, grant number 330400672559.

Institutional Review Board Statement: Not applicable.

Informed Consent Statement: Not applicable.

Data Availability Statement: The raw data required to reproduce these findings can be shared upon request.

Acknowledgments: The authors would like to thank the University of Portsmouth and Al Ain University for supporting the study.

Conflicts of Interest: The authors declare no conflict of interest.

\section{References}

1. Ayumi, N.S.; Sahudin, S.; Hussain, Z.; Hussain, M.; Samah, N.H.A. Polymeric nanoparticles for topical delivery of alpha and beta arbutin: Preparation and characterization. Drug Deliv. Transl. Res. 2019, 9, 482-496. [CrossRef] [PubMed]

2. Guterres, S.S.; Alves, M.P.; Pohlmann, A.R. Polymeric Nanoparticles, Nanospheres and Nanocapsules, for Cutaneous Applications. Drug Target Insights 2007, 2, 147-157. [CrossRef] [PubMed]

3. Haque, T.; Talukder, M.M.U. Chemical Enhancer: A Simplistic Way to Modulate Barrier Function of the Stratum Corneum. Adv. Pharm. Bull. 2018, 8, 169-179. [CrossRef] [PubMed]

4. Alkilani, A.Z.; McCrudden, M.T.C.; Donnelly, R.F. Transdermal drug delivery: Innovative pharmaceutical developments based on disruption of the barrier properties of the stratum corneum. Pharmaceutics 2015, 7, 438-470. [CrossRef] [PubMed]

5. Paudel, K.S.; Milewski, M.; Swadley, C.L.; Brogden, N.K.; Ghosh, P.; Stinchcomb, A.L. Challenges and opportunities in dermal/transdermal delivery. Ther. Deliv. 2010, 1, 109-131. [CrossRef] 
6. Nair, S.S. Chitosan-based transdermal drug delivery systems to overcome skin barrier functions. J. Drug Deliv. Ther. 2019, 9, 266-270. [CrossRef]

7. Carter, P.; Narasimhan, B.; Wang, Q. Biocompatible nanoparticles and vesicular systems in transdermal drug delivery for various skin diseases. Int. J. Pharm. 2019, 555, 49-62. [CrossRef]

8. Mishra, D.K.; Pandey, V.; Maheshwari, R.; Ghode, P.; Tekade, R.K. Cutaneous and Transdermal Drug Delivery: Techniques and Delivery Systems. In Basic Fundamentals of Drug Delivery; Elsevier: Amsterdam, The Netherlands, 2019; pp. 595-650.

9. Haghighatpanah, N.; Mirzaee, H.; Khodaiyan, F.; Kennedy, J.F.; Aghakhani, A.; Hosseini, S.S.; Jahanbin, K. Optimization and characterization of pullulan produced by a newly identified strain of Aureobasidium pullulans. Int. J. Biol. Macromol. 2020, 152, 305-313. [CrossRef]

10. Nanda, A.; Nanda, S.; Nguyen, T.A.; Slimani, Y.; Rajendran, S. Nanocosmetics: Fundamentals, Applications and Toxicity; Micro and Nano Technologies: Jaipur, India, 2020; ISBN 0128222867.

11. Li, H.; Xue, Y.; Jia, B.; Bai, Y.; Zuo, Y.; Wang, S.; Zhao, Y.; Yang, W.; Tang, H. The preparation of hyaluronic acid grafted pullulan polymers and their use in the formation of novel biocompatible wound healing film. Carbohydr. Polym. 2018, 188, 92-100. [CrossRef]

12. Vora, L.K.; Courtenay, A.J.; Tekko, I.A.; Larrañeta, E.; Donnelly, R.F. Pullulan-based dissolving microneedle arrays for enhanced transdermal delivery of small and large biomolecules. Int. J. Biol. Macromol. 2020, 146, 290-298. [CrossRef]

13. Coltelli, M.-B.; Danti, S.; De Clerck, K.; Lazzeri, A.; Morganti, P. Pullulan for Advanced Sustainable Body- and Skin-Contact Applications. J. Funct. Biomater. 2020, 11, 20. [CrossRef]

14. Sharma, D.; Kanchi, S.; Bisetty, K. Biogenic synthesis of nanoparticles: A review. Arab. J. Chem. 2019, 12, 3576-3600. [CrossRef]

15. Saratale, R.G.; Shin, H.-S.; Kumar, G.; Benelli, G.; Ghodake, G.S.; Jiang, Y.Y.; Kim, D.S.; Saratale, G.D. Exploiting fruit byproducts for eco-friendly nanosynthesis: Citrus $\times$ clementina peel extract mediated fabrication of silver nanoparticles with high efficacy against microbial pathogens and rat glial tumor C6 cells. Environ. Sci. Pollut. Res. 2018, 25, 10250-10263. [CrossRef]

16. Al-Owasi, Y.; Elshafie, A.; Sivakumar, N.; Al-Bahry, S. Synthesis of Pullulan-Mediated Silver Nanoparticles (AgNPs) and their Antimicrobial Activities. Sultan Qaboos Univ. J. Sci. 2019, 24, 88-94. [CrossRef]

17. Laksee, S.; Puthong, S.; Kongkavitoon, P.; Palaga, T.; Muangsin, N. Facile and green synthesis of pullulan derivative-stabilized Au nanoparticles as drug carriers for enhancing anticancer activity. Carbohydr. Polym. 2018, 198, 495-508. [CrossRef]

18. Ganduri, V.; Mangamuri, U.; Muvva, V.; Poda, S. Pullulan-Stabilized Silver Nanoparticles -Their Synthesis, Characterization and Application as Bactericidal Agents. J. Appl. Pharm. Sci. 2016, 6, 027-037. [CrossRef]

19. Dionísio, M.; Cordeiro, C.; Remuñán-López, C.; Seijo, B.; da Costa, A.M.R.; Grenha, A. Pullulan-based nanoparticles as carriers for transmucosal protein delivery. Eur. J. Pharm. Sci. 2013, 50, 102-113. [CrossRef] [PubMed]

20. Singh, R.S.; Kaur, N.; Rana, V.; Kennedy, J.F. Pullulan: A novel molecule for biomedical applications. Carbohydr. Polym. 2017, 171, 102-121. [CrossRef]

21. Bostanudin, M.F.; Lalatsa, A.; Górecki, D.C.; Barbu, E. Engineering butylglyceryl-modified polysaccharides towards nanomedicines for brain drug delivery. Carbohydr. Polym. 2020, 236, 116060. [CrossRef]

22. Yuan, H.; Zhong, W.; Wang, R.; Zhou, P.; Nie, Y.; Hu, W.; Tao, X.; Yang, P. Preparation of Cholesteryl-Modified Aminated Pullulan Nanoparticles to Evaluate Nanoparticle of Hydrophobic Degree on Drug Release and Cytotoxicity. J. Nanomater. 2020, $2020,1-10$. [CrossRef]

23. Zeb, A.; Arif, S.T.; Malik, M.; Shah, F.A.; Din, F.U.; Qureshi, O.S.; Lee, E.-S.; Lee, G.-Y.; Kim, J.-K. Potential of nanoparticulate carriers for improved drug delivery via skin. J. Pharm. Investig. 2019, 49, 485-517. [CrossRef]

24. Kumar, G.P.; Rajeshwarrao, P. Nonionic surfactant vesicular systems for effective drug delivery-An overview. Acta Pharm. Sin. B 2011, 1, 208-219. [CrossRef]

25. Akagi, T.; Watanabe, K.; Kim, H.; Akashi, M. Stabilization of Polyion Complex Nanoparticles Composed of Poly(amino acid) Using Hydrophobic Interactions. Langmuir 2010, 26, 2406-2413. [CrossRef]

26. Tao, X.; Jin, S.; Wu, D.; Ling, K.; Yuan, L.; Lin, P.; Xie, Y.; Yang, X. Effects of Particle Hydrophobicity, Surface Charge, Media pH Value and Complexation with Human Serum Albumin on Drug Release Behavior of Mitoxantrone-Loaded Pullulan Nanoparticles. Nanomaterials 2015, 6, 2. [CrossRef] [PubMed]

27. Desai, P.; Patlolla, R.R.; Singh, M. Interaction of nanoparticles and cell-penetrating peptides with skin for transdermal drug delivery. Mol. Membr. Biol. 2010, 27, 247-259. [CrossRef] [PubMed]

28. Lin, B.; Su, H.; Jin, R.; Li, D.; Wu, C.; Jiang, X.; Xia, C.; Gong, Q.; Song, B.; Ai, H. Multifunctional dextran micelles as drug delivery carriers and magnetic resonance imaging probes. Sci. Bull. 2015, 60, 1272-1280. [CrossRef]

29. Rokitskaya, T.I.; Korshunova, G.A.; Antonenko, Y.N. Effect of Alkyl Chain Length on Translocation of Rhodamine B n-Alkyl Esters across Lipid Membranes. Biophys. J. 2018, 115, 514-521. [CrossRef] [PubMed]

30. Li, S.; Xiong, Q.; Lai, X.; Li, X.; Wan, M.; Zhang, J.; Yan, Y.; Cao, M.; Lu, L.; Guan, J.; et al. Molecular Modification of Polysaccharides and Resulting Bioactivities. Compr. Rev. Food Sci. Food Saf. 2015, 15, 237-250. [CrossRef]

31. Bostanudin, M.F.; Noor, N.S.M.; Sahudin, S.; Lazim, A.M.; Tan, S.F.; Sarker, M.Z.I. Investigations of amphiphilic butylglycerylfunctionalized dextran nanoparticles for topical delivery. J. Appl. Polym. Sci. 2021, 138, 50235. [CrossRef]

32. Kostag, M.; Gericke, M.; Heinze, T.; El Seoud, O.A. Twenty-five years of cellulose chemistry: Innovations in the dissolution of the biopolymer and its transformation into esters and ethers. Cellulose 2019, 26, 139-184. [CrossRef] 
33. Aung, N.N.; Ngawhirunpat, T.; Rojanarata, T.; Patrojanasophon, P.; Opanasopit, P.; Pamornpathomkul, B. HPMC/PVP Dissolving Microneedles: A Promising Delivery Platform to Promote Trans-Epidermal Delivery of Alpha-Arbutin for Skin Lightening. AAPS PharmSciTech 2020, 21, 25. [CrossRef]

34. Won, J.; Park, J.W. Improvement of arbutin trans-epidermal delivery using radiofrequency microporation. Trop. J. Pharm. Res. 2014, 13, 1775. [CrossRef]

35. Easmin, S.; Sarker, M.Z.I.; Ghafoor, K.; Ferdosh, S.; Jaffri, J.M.; Akanda, M.J.H.; Al-Juhaimi, F.Y.; Bostanudin, F.M.; Khatib, A Extraction of $\alpha$-glucosidase inhibitory compounds from Phaleria macrocarpa fruit flesh using solvent, sonication, and subcritical carbon dioxide soxhlet methods. J. Food Biochem. 2017, 41, e12399. [CrossRef]

36. Aung, N.N.; Ngawhirunpat, T.; Rojanarata, T.; Patrojanasophon, P.; Pamornpathomkul, B.; Opanasopit, P. Fabrication, characterization and comparison of $\alpha$-arbutin loaded dissolving and hydrogel forming microneedles. Int. J. Pharm. 2020, 586, 119508. [CrossRef] [PubMed]

37. Liang, K.; Xu, K.; Bessarab, D.; Obaje, J.; Xu, C. Arbutin encapsulated micelles improved transdermal delivery and suppression of cellular melanin production. BMC Res. Notes 2016, 9, 254. [CrossRef] [PubMed]

38. Bostanudin, M.F.; Arafat, M.; Sarfraz, M.; Górecki, D.C.; Barbu, E. Butylglyceryl Pectin Nanoparticles: Synthesis, Formulation and Characterization. Polymers 2019, 11, 789. [CrossRef]

39. Hsu, H.-H.; Kracht, J.-K.; Harder, L.E.; Rudnik, K.; Lindner, G.; Schimek, K.; Marx, U.; Pörtner, R. A Method for Determination and Simulation of Permeability and Diffusion in a 3D Tissue Model in a Membrane Insert System for Multi-well Plates. J. Vis. Exp. 2018, 132, e56412. [CrossRef] [PubMed]

40. Hussain, M.A.; Abbas, K.; Jantan, I.; Bukhari, S.N.A. Polysaccharide-based materials in macromolecular prodrug design and development. Int. Mater. Rev. 2017, 62, 1-21. [CrossRef]

41. Culica, M.E.; Kasperczyk, K.; Baron, R.I.; Biliuta, G.; Macsim, A.M.; Lazea-Stoyanova, A.; Orlinska, B.; Coseri, S. Recyclable Polymer-Supported N-Hydroxyphthalimide Catalysts for Selective Oxidation of Pullulan. Materials 2019, 12, 3585. [CrossRef]

42. Pereira, J.M. Synthesis of New Pullulan Derivatives for Drug Delivery. Ph.D. Thesis, Virginia Polytechnic Institute and State University, Blacksburg, VA, USA, 2013.

43. Cumpstey, I. Chemical modification of polysaccharides. Int. Sch. Res. Not. 2013, 2013, 417672. [CrossRef]

44. Caine, D. Potassium tert-Butoxide. Encycl. Reag. Org. Synth. 2001. [CrossRef]

45. Li, W.; Zhou, P.; Li, G.; Lin, L.; Feng, X. Catalytic Asymmetric Halohydroxylation of $\alpha$, $\beta$-Unsaturated Ketones with Water as the Nucleophile. Adv. Synth. Catal. 2020, 362, 1982-1987. [CrossRef]

46. Saber-Samandari, S.; Gulcan, H.O.; Saber-Samandari, S.; Gazi, M. Efficient Removal of Anionic and Cationic Dyes from an Aqueous Solution Using Pullulan-graft-Polyacrylamide Porous Hydrogel. Water Air Soil Pollut. 2014, 225, 1-14. [CrossRef]

47. Chen, L.; Wang, X.; Ji, F.; Bao, Y.; Wang, J.; Wang, X.; Guo, L.; Li, Y. New bifunctional-pullulan-based micelles with good biocompatibility for efficient co-delivery of cancer-suppressing p53 gene and doxorubicin to cancer cells. RSC Adv. 2015, 5, 94719-94731. [CrossRef]

48. Wang, X.; Zhang, M.; Xing, F.; Han, N. Effect of a healing agent on the curing reaction kinetics and its mechanism in a self- healing system. Appl. Sci. 2018, 8, 2241. [CrossRef]

49. Panda, H. Epoxy Resins Technology Handbook (Manufacturing Process, Synthesis, Epoxy Resin Adhesives and Epoxy Coatings); Asia Pacific Business Press Inc.: New Delhi, India, 2019; ISBN 8178331829.

50. Qin, Z.-Y.; Jia, X.-W.; Liu, Q.; Kong, B.-H.; Wang, H. Fast dissolving oral films for drug delivery prepared from chitosan/pullulan electrospinning nanofibers. Int. J. Biol. Macromol. 2019, 137, 224-231. [CrossRef] [PubMed]

51. Li, H.; Yu, H.; Liu, Y.; Wang, Y.; Li, H.; Yu, J. The use of of inulin, maltitol and lecithin as fat replacers and plasticizers in a model reduced-fat mozzarella cheese-like product. J. Sci. Food Agric. 2019, 99, 5586-5593. [CrossRef] [PubMed]

52. Guidara, M.; Yaich, H.; Richel, A.; Blecker, C.; Boufi, S.; Attia, H.; Garna, H. Effects of extraction procedures and plasticizer concentration on the optical, thermal, structural and antioxidant properties of novel ulvan films. Int. J. Biol. Macromol. 2019, 135, 647-658. [CrossRef]

53. Bizot, H.; Le-Bail, P.; Leroux, B.; Davy, J.; Roger, P.; Buleon, A. Calorimetric evaluation of the glass transition in hydrated, linear and branched polyanhydroglucose compounds. Carbohydr. Polym. 1997, 32, 33-50. [CrossRef]

54. Roos, Y.H.; Drusch, S. Phase Transitions in Foods; Academic Press: Cambridge, MA, USA, 2015; ISBN 0124079229.

55. Karakus, S.; Tan, E.; Ilgar, M.; Kahyaoglu, I.M.; Şahin, Y.M.; Mansuroglu, D.S.; Ismik, D.; Tasaltin, N.; Kilislioglu, A. Preparation, Characterization, and Swelling Behavior of PEGylated Guar Gum @ Ag Nanoparticles. In Sonochemical Reactions; IntechOpen: London, UK, 2019.

56. Lapčík, L., Jr.; Benešová, K.; Lapčík, L.; De Smedt, S.; Lapčíková, B. Chemical modification of hyaluronic acid: Alkylation. Int. J. Polym. Anal. Charact. 2010, 15, 486-496. [CrossRef]

57. Chen, N.-X.; Zhang, J.-H. The role of hydrogen-bonding interaction in poly(vinyl alcohol)/poly(acrylic acid) blending solutions and their films. Chin. J. Polym. Sci. 2010, 28, 903-911. [CrossRef]

58. Lee, S.J.; Hong, G.-Y.; Jeong, Y.-I.; Kang, M.-S.; Oh, J.-S.; Song, C.-E.; Lee, H.C. Paclitaxel-incorporated nanoparticles of hydrophobized polysaccharide and their antitumor activity. Int. J. Pharm. 2012, 433, 121-128. [CrossRef]

59. Topel, Ö.; Çakır, B.A.; Budama, L.; Hoda, N. micelle Determination of critical concentration of polybutadiene-blockpoly(ethyleneoxide) diblock copolymer by fluorescence spectroscopy and dynamic light scattering. J. Mol. Liq. 2013, 177, 40-43. [CrossRef] 
60. Shah, M.; Choi, M.H.; Yoon, S.C. Amphiphilic polymeric nanoparticles for drug delivery: Synthesis and characterization. In Proceedings of the ICONN 2010-2010 International Conference on Nanoscience and Nanotechnology, Sydney, NSW, Australia, 22-26 February 2010.

61. Akagi, T.; Baba, M.; Akashi, M. Preparation of nanoparticles by the self-organization of polymers consisting of hydrophobic and hydrophilic segments: Potential applications. Polymer 2007, 48, 6729-6747. [CrossRef]

62. Barichello, J.M.; Morishita, M.; Takayama, K.; Nagai, T. Encapsulation of Hydrophilic and Lipophilic Drugs in PLGA Nanoparticles by the Nanoprecipitation Method. Drug Dev. Ind. Pharm. 1999, 25, 471-476. [CrossRef]

63. Liao, A.-H.; Ma, W.-C.; Wang, C.-H.; Yeh, M.-K. Penetration depth, concentration and efficiency of transdermal $\alpha$-arbutin delivery after ultrasound treatment with albumin-shelled microbubbles in mice. Drug Deliv. 2014, 23, 2173-2182. [CrossRef] [PubMed]

64. Lambers, H.; Piessens, S.; Bloem, A.; Pronk, H.; Finkel, P. Natural skin surface pH is on average below 5, which is beneficial for its resident flora. Int. J. Cosmet. Sci. 2006, 28, 359-370. [CrossRef]

65. Wang, Y.-H.; Avonto, C.; Avula, B.; Wang, M.; Rua, D.; Khan, I.A. Quantitative Determination of $\alpha$-Arbutin, $\beta$-Arbutin, Kojic Acid, Nicotinamide, Hydroquinone, Resorcinol, 4-Methoxyphenol, 4-Ethoxyphenol, and Ascorbic Acid from Skin Whitening Products by HPLC-UV. J. AOAC Int. 2015, 98, 5-12. [CrossRef]

66. Gouda, R.; Baishya, H.; Qing, Z. Application of mathematical models in drug release kinetics of carbidopa and levodopa ER tablets. J. Dev. Drugs 2017, 6, 1-8.

67. Azadi, S.; Ashrafi, H.; Azadi, A. Mathematical modeling of drug release from swellable polymeric nanoparticles. J. Appl. Pharm. Sci. 2017, 7, 125-133.

68. Son, G.-H.; Lee, B.-J.; Cho, C.-W. Mechanisms of drug release from advanced drug formulations such as polymeric-based drug-delivery systems and lipid nanoparticles. J. Pharm. Investig. 2017, 47, 287-296. [CrossRef]

69. Lee, J.H.; Yeo, Y. Controlled drug release from pharmaceutical nanocarriers. Chem. Eng. Sci. 2015, 125, 75-84. [CrossRef]

70. Kamaly, N.; Yameen, B.; Wu, J.; Farokhzad, O.C. Degradable Controlled-Release Polymers and Polymeric Nanoparticles: Mechanisms of Controlling Drug Release. Chem. Rev. 2016, 116, 2602-2663. [CrossRef] [PubMed]

71. Morris, G.A.; Castile, J.; Smith, A.; Adams, G.G.; Harding, S.E. The effect of prolonged storage at different temperatures on the particle size distribution of tripolyphosphate (TPP)—Chitosan nanoparticles. Carbohydr. Polym. 2011, 84, 1430-1434. [CrossRef]

72. Mahmoudi, S.; Jafari, A.; Javadian, S. Temperature effect on performance of nanoparticle/surfactant flooding in enhanced heavy oil recovery. Pet. Sci. 2019, 16, 1387-1402. [CrossRef]

73. Alameda, J.P.; Navarro, M.; Ramírez, Á.; Page, A.; Suárez-Cabrera, C.; Moreno-Maldonado, R.; Paramio, J.M.; del Carmen Fariña, M.; Del Río, M.; Fernández-Aceñero, M.J.; et al. IKK $\alpha$ regulates the stratification and differentiation of the epidermis: Implications for skin cancer development. Oncotarget 2016, 7, 76779. [CrossRef]

74. Bostanudin, M.F.; Salam, A.; Mahmood, A.; Arafat, M.; Kaharudin, A.N.; Sahudin, S.; Lazim, A.M.; Azfaralariff, A. Formulation and In-Vitro Characterisation of Cross-linked Amphiphilic Guar Gum Nanocarriers for Percutaneous Delivery of Arbutin. J. Pharm. Sci. 2021. [CrossRef]

75. Vavrova, K.; Zbytovska, J.; Hrabálek, A. Amphiphilic Transdermal Permeation Enhancers: Structure-Activity Relationships. Curr. Med. Chem. 2005, 12, 2273-2291. [CrossRef] [PubMed]

76. Li, N.; Quan, P.; Wan, X.; Liu, C.; Liu, X.; Fang, L. Mechanistic insights of the enhancement effect of sorbitan monooleate on olanzapine transdermal patch both in release and percutaneous absorption processes. Eur. J. Pharm. Sci. 2017, 107, 138-147. [CrossRef] [PubMed]

77. Liu, L.; Zhu, L.; Gong, K.; Zhi, X.; Guan, Y.; Cai, W. Identification of the Constituents of Percutaneous Absorption from Duhaldea nervosa Based on UHPLC-Q-Exactive Orbitrap MS and Microdialysis Technique. Int. J. Anal. Chem. 2019, $2019,8328942$. [CrossRef] [PubMed]

78. OECD. Guidance Document for the Conduct of Skin Absorption Studies; OECD: Paris, France, 2004; pp. 1-31.

79. Dragicevic, N.; Maibach, H.I. Percutaneous Penetration Enhancers Drug Penetration into/through the Skin: Methodology and General Considerations; Springer: Berlin/Heidelberg, Germany, 2017; ISBN 3662532700. 